Human Evolution

Elsevier Editorial System(tm) for Journal of

Manuscript Draft

Manuscript Number: HUMEV-T-16-00456R1

Title: Pounding tools in HWK EE and EF-HR (Olduvai Gorge, Tanzania): percussive activities in the Oldowan - Acheulean transition

Article Type: SI: Oldowan-Acheulean

Keywords: Battered tools; Early Homo; Subsistence strategies; Early Stone Age; use-wear analysis

Corresponding Author: Dr. Adrian Arroyo, Ph.D.

Corresponding Author's Institution: University College London

First Author: Adrian Arroyo, Ph.D.

Order of Authors: Adrian Arroyo, Ph.D.; Ignacio de la Torre, Professor

Abstract: In this paper, we present pounded objects from excavations at HWK EE and EF-HR, which are studied from macro and microscopic perspectives. Analysis of HWK EE revealed one of the largest collections of percussive objects from Olduvai Gorge, while excavations at EF-HR have allowed us to recover a much wider collection of percussive tools than previously recorded. Differences are observed between the two localities: at the Acheulean site of EF-HR, percussive tools were predominantly used in the production of flakes and large cutting tools (LCTs). At the Oldowan site of $\mathrm{HWK} E \mathrm{E}$, the tool repertoire probably related to a wider range of activities, including bone breaking and bipolar knapping. Comparison of these two assemblages, potentially produced by different hominin species, helps provide a wider picture of pounding activities during the Oldowan - Acheulean transition at Olduvai Gorge. 


\section{Pounding tools in HWK EE and EF-HR (Olduvai Gorge, Tanzania): percussive}

2 activities in the Oldowan - Acheulean transition

3

4 Adrián Arroyo $^{1}$, Ignacio de la Torre ${ }^{1}$

5

$6 \quad{ }^{1}$ Institute of Archaeology, University College London. 31-34 Gordon Square, London, WC1H OPY, UK

7

$8 \quad *$ Corresponding author: a.arroyo @ucl.ac.uk (A. Arroyo)

\section{Abstract}

11 In this paper, we present pounded objects from excavations at HWK EE and EF-HR, which

12 are studied from macro and microscopic perspectives. Analysis of HWK EE revealed one of

13 the largest collections of percussive objects from Olduvai Gorge, while excavations at EF-HR

14 have allowed us to recover a much wider collection of percussive tools than previously

15 recorded. Differences are observed between the two localities: at the Acheulean site of EF-

16 HR, percussive tools were predominantly used in the production of flakes and large cutting

17 tools (LCTs). At the Oldowan site of HWK EE, the tool repertoire probably related to a wider range of activities, including bone breaking and bipolar knapping. Comparison of these two assemblages, potentially produced by different hominin species, helps provide a wider picture of pounding activities during the Oldowan - Acheulean transition at Olduvai Gorge.

\section{Keywords}

23 Battered tools; Early Homo; Subsistence strategies; Early Stone Age; use-wear analysis. 


\section{Introduction}

Interest in determining the function of percussive tools began early in African Stone

Age studies, as illustrated by debate on the use of so-called 'bolas' and spheroids (Gobert, 1910; Leakey, 1931; 1950; Clark, 1955; Leakey, 1971; Schick and Toth, 1994; Willoughby, 1985). Since then, researchers have included pounding tools in their technological analyses of

Early Stone Age assemblages documented across the East African Rift valley (e.g. Leakey, 1971; Isaac, 1997; Piperno et al., 2004; Chavaillon, 2004; Delagnes and Roche, 2005; Mora and de la Torre, 2005). More recent research has developed techniques to differentiate marks caused by natural agents from use-wear traces produced during percussive activities (Caruana et al., 2014). This has been accompanied by the development of more quantitative approaches to the study of wear traces on pounding tools (de la Torre et al., 2013; Caruana et al., 2014; Benito-Calvo et al., 2015).

Functional analysis through microscopic studies has been extensively used to assess activities on Palaeolithic sites. Despite the limited number of use-wear analyses conducted specifically on Early Stone Age (ESA) assemblages to study the function of flakes (e.g. Keeley and Toth, 1981; Sussman, 1987), new investigations have shown that hominins manufactured and used stone tools to consumed not only meat but also a variety of plants (Lemorini et al., 2014; Melamed et al., 2016), emphasizing the diversity of hominin diet. It has been hypothesized that during the ESA hominins used percussive tools to process nuts (Goren-Inbar et al., 2002; 2014; 2015), as well as plants and meat (e.g. Willoughby, 1985; de la Torre et al., 2013). Taphonomic studies have shown that hominins broke bones to access marrow (Bunn, 1981; Blumenschine and Selvaggio, 1988; Pobiner, 2007; Pobiner et al., 2008; Ferraro et al., 2013). Others have noted the benefits of pounding food in the absence of fire (Carmody and Wrangham, 2009), and the importance of consuming nuts, fruits and tubers as a source of nutrients (Peters, 1987). Primatological studies show that nuts, 
processed through pounding activities, represent an important source of food for West African chimpanzees (Yamakoshi, 1998), and ethnographic studies indicate the importance of percussive activities among hunter-gatherers (Murray et al., 2001).

In her seminal publication on Olduvai Gorge Mary Leakey (1971) described a series of objects under the category of 'utilised material', which grouped tools bearing percussive traces such as anvils and hammerstones. Subsequent re-analysis of Olduvai lithic assemblages emphasized the importance of these objects during Bed I and II times (Mora and de la Torre, 2005). Others have examined the function of pounding tools from Olduvai Gorge through experimental programmes (e.g. de la Torre et al., 2013; Sánchez-Yustos et al., 2015), began to apply microscopic analyses to the study of archaeological pounding tools (Arroyo and de la Torre, 2016), and compared them with chimpanzee nut cracking stone tools (Arroyo et al., 2016). The next step in percussive tool research is to expand these new protocols on experimental objects, and use such framework to undertake functional analysis of archaeological assemblages.

In this paper, we present a comprehensive study of percussive objects excavated by the Olduvai Geochronology Archaeology Project (OGAP) in the HWK EE and EF-HR localities. HWK EE, a late Oldowan site, was originally excavated by Mary Leakey after she had prepared her 1971 monograph, and the assemblage remained unpublished (Pante and de la Torre, submitted). Renewed excavations at this locality by OGAP have produced a detailed record of the stratigraphic sequence, in the transition from Lower to Middle Bed II (around 1.7 Ma), and revealed one of the largest Oldowan collection of stone tools and fossil assemblages (de la Torre et al., submitted 'a').

The Acheulean site of EF-HR was discovered in 1931, and is a well-known locality on the north side of the Gorge, about $1.2 \mathrm{~km}$ from the Third Fault (Leakey, 1971). The age of 
OGAP has refined its stratigraphic position, and located this site above Tuff IIC and therefore within Upper Bed II (de la Torre et al, submitted 'b'; McHenry, submitted).

In this study, we present a systematic technological and microscopic analysis of a large sample of percussive tools from HWK EE and EF-HR, and compare them with results from other Beds I and II pounding tools (Arroyo and de la Torre, 2016), as well as experimental tools made from Olduvai quartzite (de la Torre et al., 2013; Arroyo et al., 2016). Overall, our aim is to discuss differences on the type of pounding tools across the Oldowan-Acheulean transition at Olduvai Gorge, thus contributing to a better understanding of variations in technological and functional patterns.

This study is the first systematic functional analysis of complete assemblages of percussive tools from late Oldowan and Acheulean sites. In addition to shed new light on hominin tool use and subsistence strategies, and complement the technological analysis of the lithic assemblages (de la Torre and Mora, submitted ' $a$ ' and ' $b$ '), our use-wear contribution aims to serve as a reference for the identification of pounding tools in other African ESA sites, and set the foundations for a better understanding of their function.

\section{Materials and methods}

\subsection{The percussive assemblages from HWK EE and EF-HR}

The HWK EE percussive collection presented here (T1-Main Trench and satellite trenches [T27, T28 and T29]) consists of 349 pounded objects (representing 1.93\% of the stone tool assemblage $[n=18,107]$ collected from the four trenches) (de la Torre et al., submitted ' $a$ '). As such, HWK EE has one of the largest concentrations of percussive tools in Bed I and Bed II localities (Table 1). Complete objects form 59.3\% ( $n=207)$ of the studied assemblage, $35.2 \%(n=123)$ are fractured percussive tools, and $5.4 \%(n=19)$ are hammerstone flakes/ fragments. Most percussive objects $(n=293$ [84\%]) were recovered 
102 from the T1-Main Trench, 3.7\% $(n=13)$ from Trench 27, 6\% $(n=21)$ from Trench 28, and $1036.3 \%(n=22)$ from Trench 29 (see details in de la Torre et al., submitted 'a').

Insert Table 1

106

Percussive tools from HWK EE are most abundant in archaeological layers within the Lower Augitic Sandstone (LAS) $(n=283[81.1 \%])$ and the Lemuta member (LEM) $(n=58$ interval, Tuff IIB zone (descriptions in de la Torre et al., submitted 'a') (SOM 1-A). Leakey (1971) only refers to the presence of 4 hammerstones and 10 utilised cobbles at EF-HR. Renewed excavations at this locality by OGAP unearthed 50 percussive objects

113 (Table 1), most from levels L2 $(n=44)$ and L1 $(n=3)$ in the T2-Main Trench, and three from trench T12. 50\% $(n=25)$ of EF-HR pounding tools were found in a sandy context, $28 \%(n=$ 14 ) on clay, 20\% ( $n=10$ ) on gravel, and just one object (2\%) came from within the clay (see stratigraphic details in de la Torre et al., submitted 'b') (SOM 1-B). Conservation of percussive tools shows differences according to raw material.

118 Generally, quartzite pounding tools are well preserved; there is a low incidence of surface abrasion, with a few examples at HWK EE $(n=4)$ having scattered, abraded zones (except for one which has concentrated areas of abrasion). On the other hand, lava objects from both

121 sites (although particularly EF-HR) show variable degrees of weathering, i.e. post122 depositional chemical alterations (e.g. van Gijn, 1990; Asryan et al., 2017). Under the binocular microscope, grains of these altered tools appear rounded and have a slight sheen. At EF-HR there are examples of tools affected by grain rounding $(n=13)$, exfoliation $(n=2)$ and surface cracks $(n=8)$. 
Pounded tools were grouped into two main categories, namely active and passive elements, following Chavaillon's (1979) terminology. Techno-typological classification is

130 based on Leakey (1971) and Mora and de la Torre (2005), and a brief description of each

131 technological category is given in Table 2. Also recorded were general features such as

132 battered areas, number of working surfaces and fractures. Raw material classification is based on McHenry and de la Torre (submitted).

Insert Table 2

136

In addition to the qualitative analysis of all percussive tools, in the case of subspheroids and hammerstones with fracture angles (HFA) we also performed statistical tests to characterise and compare their shape. This aims to shed light on the long-standing discussion on whether or not the spherical form of subshperoids is intentional (e.g. Schick and Toth, 1994; Texier and Roche, 1995). To avoid the bias introduced by raw material and blank variability, all HFA and subspheroids selected for statistical analysis are of the same raw material (i.e. quartzite). Shape analysis was undertaken using orthogonal digital images

144 of subspheroids and HFA and processed with ImageJ (Rasband, 1997), following protocols similar to Tanabata et al. (2012). General morphological parameters (i.e. tool area and

146 perimeter) were calculated, as well as various shape descriptors used in particle analysis, such 147 as aspect ratio (which measures the proportional relationship between length and width), 148 solidity (which measures the overall concavity of the shape), roundness and circularity (both 149 parameters used to calculate the closest fit of tool shape to a circle, which is represented by a 150 value of one) (Olson, 2011). Image $\mathbf{J}$ was also employed to obtain additional quantitative 151 data, and to calculate the area of battered marks and depressions. 

experimental reference collection of Olduvai objects used by modern humans (de la Torre et al., 2013) and captive chimpanzees (Arroyo et al., 2016). Quantitative data collected during the macroscopic analysis was processed using PAST (Hammer et al., 2001) and SPSS packages.

All percussive objects were inspected to assess their suitability for microscopic analysis. Microscopic analysis was undertaken primarily on quartzite percussion objects $(n=$ 38) because their state of conservation was better than tools of other raw materials. However, volcanic $(n=10)$ and gneiss $(n=1)$ pieces were also selected. Prior to analysis, all objects were gently cleaned with water to eliminate dust and superficial sediment. between $1 \mathrm{x}$ and $8 \mathrm{x}$, equipped with $10 \mathrm{x}$ ocular lenses, fiber optic illumination and a digital camera EC3). This conforms with procedures used on pounding and grinding tools from later prehistoric periods (e.g. Adams, 1993; 2002; Adams et al., 2009; Dubreuil, 2001; 2004; Hamon, 2008), as well as on ESA flakes (e.g. Lemorini et al., 2014). The same methodology has also been applied to analysis of archaeological pounding tools from Olduvai Beds I and II

170 (Arroyo and de la Torre, 2016) and experimental anvils (de la Torre et al., 2013), and aids the characterization of use-wear traces on medium-to-large size objects which cannot be studied using a high magnification approach with scanning electron microscopes (SEM).

174 produced through a tribological mechanism of fatigue wear (Kato, 2002) (e.g. pits, micro-

175 fractures, crystal/grain crushing, impact points and micro-fractures), or due to a process of 176 abrasive wear, e.g. linear traces, polish (Adams et al., 2009) and abrasion (Keeley, 1980). 


\subsection{Techno-typological analysis}

HWK EE has a greater variety of percussive tools than EF-HR (Table 1); active

180 elements are dominated by knapping hammerstones and fractured hammerstones $(n=242)$,

181 with a significant presence of hammerstones with fracture angles (HFA) $(n=19)$,

182 hammerstones with active edges (HAE) $(n=20)$ and subspheroids $(n=12)$. Passive elements

183 are represented by passive hammerstones with friction marks (PHFM) $(n=2)$ and anvils $(n=$

184 9), the latter having the largest mean dimensions (Table 3 and Figure 1). There are also pitted 185 stones $(n=19)$ which could have been used as passive or active elements. We have not 186 identified clear passive elements in EF-HR, and the percussive assemblage is dominated by 187 knapping hammerstones and fractured hammerstones $(n=38)$, followed by HFA $(n=7)$, HAE $(n=3)$, and pitted stones $(n=2)$ (Table 3 and Figure 1$)$.

Insert Figure 1

Normality tests, run for each technological category to allow statistical comparison of both assemblages, show that artefact samples do not all have a normal distribution in length and weight parameters $(p<0.05)$. Non-parametric Mann-Whitney $\mathrm{U}$ tests for the percussive assemblages from HWK EE and EF-HR show significant differences in length $(z=-5.970, p$

$196(2$-tailed $)<0.05)$ and weight $(z=-6.190, p(2$-tailed $)<0.05)$. These statistical results,

197 illustrated in Figure 2A, show that the EF-HR percussive objects tend to have higher mean 198 dimensions than those from HWK EE.

Insert Table 3

Insert Figure 2 

trachyte/trachyandesite, and phonolite having similar percentages $(23.9 \%, 22.1 \%$ and $22.7 \%$ respectively) (see Table 4). Basalt (38\%) and trachyte/trachyandesite (24\%) are the predominant raw materials at EF-HR, followed by phonolite (22.0\%), quartzite $(14.0 \%)$ and gneiss $(2.0 \%)$. The Chi square test indicates no significant overall differences in raw material per site $\left(x^{2}=7.562, \mathrm{df}=3, p=0.056\right)$, although when adjusted residual values are considered, HWK EE shows a higher frequency of quartzite percussive tools. While preferential use of cobbles as blanks is indicated at both sites, blocks are also well represented at HWK EE (Table 5).

\section{Insert Table 4}

Insert Table 5

\subsubsection{Active elements}

Knapping hammerstones

Knapping hammerstones (including fractured knapping hammerstones) are the most common pounding tool of all percussive objects at both EF-HR $(76 \% n=38)$ and HWK EE $(71.4 \% n=242)($ Table 1$)$, and are primarily on cobble blanks $(n=90$ [75.6\%] at HWK EE; $n=23[76.7 \%]$ at EF-HR), most often trachyte/trachyandesite and basalts (Table 4). Although the HWK EE knapping hammerstones do not follow a normal distribution in length and weight (Shapiro-Wilk test, $p<0.05$ ), the Mann-Whitney U non-parametric test revealed significant differences in length, width and weight $(p(2$-tailed $)<0.05$ on the three variables $)$, with a group of EF-HR hammerstones having larger dimensions (Figure 2C).

Despite size differences, all knapping hammerstones display similar use-wear patterns 
least at one end of the blank, as well as impact points scattered across the surfaces. and contact with hard material. The HWK EE knapping hammerstones usually have one working zone, with percussive traces on small areas of their surface, although rare pieces display several working zones (Figure 3A). The EF-HR knapping hammerstones show a greater degree of use and have multiple zones with battering marks covering large portions of the surface, suggesting deliberate re-orientation of the tool during use in search of convex areas (Figure 3B).

Insert Figure 3

Hammerstones with an active edge (HAE)

The Mann-Whitney U test reveals no significant differences in length between the three HAE at EF-HR and the twenty at HWK EE $(z=-.594 ; p$ (2-tailed $)=0.552)$; width $(z=-$ $.927 ; p(2$-tailed $)=0.927)$ and weight $(z=-.091 ; p(2$-tailed $)=0.927)($ Figure $2 \mathrm{D})$.

The HAE from EF-HR are on lava (basalt $[n=1]$ and phonolite $[n=2]$ ) cobbles; at HWK EE, six are on blocks and five on cobbles, while blanks for the remaining nine pieces are indeterminate. At both sites, these objects bear percussive marks on one or two angular areas, opposite an unmodified natural surface (Figure 4). Although use-wear distribution is similar, there are differences between HAE on lava and those on quartzite. Lava HAE from both sites show intense damage on one working zone (Figure 4B and SOM 2), characterized by invasive battering marks and the presence of multiple step and hinge fractures with no preferential orientation. In contrast, quartzite HAE (present only at HWK EE) have superficial percussive marks formed by repetitive impact points along one edge (Figure 4A). 


\section{Subspheroids}

Subspheroids were identified solely at HWK EE $(n=12$ [3.6\%]) (Figure 5), but the original blank could be determined only in two (one cobble and one block, both quartzite). In size, they are similar to the knapping hammerstones from the site (Table 3), but the MannWhitney $\mathrm{U}$ test indicates significant differences in length $(z=-2.678 ; p(2$-tailed $)=0.007)$, but not weight $(z=-1.025 ; p(2$-tailed $)=0.305)$. Most subspheroids $(n=9)$ have several working zones with isolated battered areas and impact points scattered across both flaked zones and 261 edges.

Six subspheroids are multifacial cores, dominated by secant scars flaked from multiple knapping platforms. Battering marks on these objects are located mainly on ridges, and some impact points are visible inside flake scars. The latter suggests that flaking took place before the tools were used in percussive activities (Figure 6A). It was not possible to determine the sequential use of blanks for the remaining subspheroids $(n=6)$ as no overlapping occurs between percussive traces and flake scars (Figure 6B).

Insert Figure 5

Insert Figure 6

$5.8 \%(n=19)$ of the HWK EE pounded tools and $14 \%(n=7)$ at EF-HR, were EE, with significant differences in length and weight (T-test, $p<0.05$ ). The EF-HR tools are 
bearing battered areas associated with multidirectional, non-invasive, step fractures. Those at HWK EE were mainly on cobbles $(n=13)$, mostly basalt $(n=8)$, followed by quartzite $(n=6)$, trachyte/trachyandesite $(n=3)$ and phonolite $(n=2)$. They show similar percussive patterns to those from EF-HR, with lava HFA bearing more intense fracturing of the active surface than their quartzite counterparts.

HFA show no clear signs of flaking, and damage is related primarily with percussive motions. All display battering scattered across the surface, located mainly in distal and convex zones, covering small areas, and occasionally associated with macrofractures having semicircular, wide and short morphologies. The morphometric and shape characteristics of HFA (Table 6) show no significant differences in area and perimeter (Kruskal-Wallis test, $p>$ 0.05) when compared to subspheroids. The Kruskal-Wallis non-parametric test shows no significant differences in roundness $(p=0.212)$, solidity $(p=0.077)$ and aspect ratio $(p=$ 0.212) between subspheroids and HFA.

\section{Insert Table 6}

\subsubsection{Active/ passive elements: pitted stones}

The pitted stones from HWK EE $(n=19)$ are on lava cobbles (basalt [42.1\%], phonolite [36.8\%], trachyte/trachyandesite [15.8\%] and pumice [5.3\%]), while those at EFHR $(n=2)$ are on basalt cobbles (Table 4 and 5). The EF-HR pitted stones have higher mean dimensions and weight than the HWK EE pieces (Table 3 and Figure 2F).

Pitted stones usually have a single working zone on one face of the cobble, although some of the HWK EE specimens $(n=5)$ show several working zones located on the horizontal plane and on the convex ends of blanks. The main macroscopic use-wear feature is a depression which tends to be circular and/or oval in morphology (Figure 7). One example 
from HWK EE shows a depression on one horizontal plane in addition to battering marks on the proximal zone of the right lateral plane, a large step fracture, and two possible flake scars (Figure 7C and SOM 4). Such multiuse of a pitted stone was also identified on a second object, in which the exploitation surface is opposite the location of the depression (SOM 4).

Analysis of six pitted stones from HWK EE provided a mean area fur such pits of (such as tool HWKEE L6-981) with angular profiles (SOM 3). The inner areas of depressions in some pitted stones (e.g. HWKEE L1-2735 and HWKEE L6-981, SOM 3) have a uniform, polished surface, but in general surfaces tend to be irregular.

Insert Figure 7

\subsubsection{Passive elements (anvils)}

This group includes nine percussive objects from HWK EE, whose mean dimensions are larger than the active elements (Table 3). They are all on tabular quartzite blocks and have one or two working zones on the horizontal plane. Three anvils show small battered areas covering less than $5 \%$ of the surface. On two of these anvils, an additional battered area is located on a transversal plane; as the anvils could not have been stationary due to their lack of stability, these tools may also have used as active elements. the contact between the horizontal and lateral planes (Figure 8B). Occasionally $(n=4)$, these impacts are associated with unidirectional, superimposed macro-fractures, normally wide and short in morphology, with step terminations located on one edge and associated with battering marks (Figure 8C). Included in the passive element group, are two lava PHFM 
327 friction motion producing an abraded surface.

328

Insert Figure 8

330

\subsubsection{Utilised material and other tools with percussive marks}

333

334

335

336

337

338

339

340

Insert Table 7 groups.

At HWK EE, 2.1\% (n=7) of percussive objects were classified as utilised materials other than the categories described above; all are on quartzite tabular blocks and have at least one possible working zone on a horizontal plane, on which there are superficial wear traces characterised by isolated and scattered impact points. The absence of fractures or battered areas of utilised materials hinders their categorisation within any of the previous percussive

Included in the two assemblages analysed here are some flakes (EF-HR: 0.38\%; HWK EE: $5.56 \%$ of total flakes), flake fragments (EF-HR: $1.47 \%$; HWK EE: $3.80 \%$ of total flake fragments), cores (EF-HR: 20.14\%; HWK EE: $23.46 \%$ of total cores) and chunks (EFHR: $0.83 \%$; HWK EE: $14.21 \%$ of total chunks), with percussive marks on their surfaces (Table 7). Battering marks could have been produced on these detached pieces either by a non-knapping percussive task, or during core flaking. Écaillé marks were also found on cores, flakes, flake fragments and chunks (Table 7).

Battering marks on cores are normally located on the side opposite the flaking surface. In these cases, use of the blank as a pounding tool seems to have occurred first, as otherwise the knapping edge would have hindered manipulation of the blank during battering. 

anvils $(n=7)$, knapping hammerstones/fractured hammerstones $(n=12)$, HAE $(n=8)$, HFA $(n=6)$, subspheroids $(n=11)$ and core-hammerstones $(n=3)$. They are on various raw materials (HWK EE: quartzite: $n=35$; basalt: $n=2$; phonolite: $n=2$; pumice: $n=1$; trachyte/trachyandesite: $n=2$; EF-HR: basalt: $n=1$; trachyte/trachyandesite: $n=2$; gneiss: $n=$ 1; quartzite: $n=3$ ) (Table 8).

Table 9 summarizes microscopic percussive traces identified on pounding tools from both sites. $70.4 \%$ of the EF-HR tools studied and $85.7 \%$ of HWK EE pieces show crystal and grain crushing on their surfaces, frequently associated with micro-fractures and having a stepped morphology (present on 15 percussive tools, 30.6\%). A few percussive tools $(n=18$ combination of both types of micro-fractures, caused by the detachment of small crystal/grain fragments.

Insert Table 8

Insert Table 9

Microscopic percussive traces are associated with a fatigue wear mechanism (sensu Adams et al., 2009) produced by a thrusting percussion motion. As no major differences were found between HWK EE and EF-HR on pits, micro-fractures, impacts and crushing (Mann-

374 Whitney $\mathrm{U}, p>0.05)$, results of both sites are based on the general classification of objects

375 (passive vs active elements). Only one tool from HWK EE showed traces that can be linked 376 to an abrasive wear mechanism. 

impact points of irregular/circular morphology, were common on anvils (Figure 8A-2), and superficially affect the grain structure of blanks. Crushed areas (Figure 8C-2) are mainly associated with micro-fractures of irregular $(n=4)$ or stepped $(n=1)$ morphology (Figure 8A1). Only one anvil displays an intense battered area associated with the development of pits and detachment of small crystal fragments. The horizontal plane of another anvil shows a cluster of parallel, linear traces, 'U'-shaped in section whose maximum length is $20-30 \mathrm{~mm}$ (Figure 9A-1). The high incidence and length of these linear traces suggest a sliding movement against a hard material. best preserved, were selected for microscopic study. In both cases, use-wear patterns of depressions are similar; surfaces are affected by a process of grain fracturing and detachment associated with grain crushing (Figure 7B). The lack of linear traces can be related to the absence of sliding movements during use, and the formation of depressions are the result of thrusting percussion.

Insert Figure 9

Linear traces are absent in all analysed active elements. Impact points $(n=36)$ and crushed areas $(n=34)$ are the most common percussive traces (Figure 10). Pits show an angular /concave morphology and diameter $<1 \mathrm{~mm}$, and were identified mainly on knapping hammerstones $(n=4)$ and subspheroids $(n=3)$ from HWK EE. These pits identified in subspheroids and hammerstones can be linked with an intense use, as indicated by the greater occurrence of percussive traces on blanks. Micro-fractures on tools $(n=34)$, common on the

401 battered areas of active elements, are generally stepped in morphology $(n=18)$. 

with percussive traces located on angular areas, show the development of slight rounding and compression of the edge caused by micro-fracturing of crystals (Figure 9B). These microfractures diverge in opposite directions and progressively break the active edge causing it to become blunt. The process is more superficial on the HAE specimens due to the low incidence of percussive traces, while on knapping hammerstones the degree of roundness in battered areas is more evident.

Insert Figure 10

\section{Discussion}

\subsection{Percussive activities at HWK EE and EF-HR} EF-HR; the earlier assemblage (HWK EE) displays a relatively homogenous size distribution, while at EF-HR it is possible to distinguish a second group of hammerstones larger than 10 $\mathrm{cm}$, which often bear a higher incidence of traces on the surface.

This size variation of knapping hammerstones is connected with the chaîne opératoire at each site. At EF-HR, the production of large flakes and LCTs (de la Torre and Mora, submitted ' $b$ ') requires larger hammerstones. In contrast, the selection of cobbles for use as hammerstones in HWK EE is adapted to a chaîne opératoire of small debitage (de la Torre and Mora, submitted 'a'). The presence of cores with percussive marks (Table 7) highlights the multi-functionality of these tools. Thus, in both Oldowan and Acheulean assemblages analysed, re-utilisation of objects as battering and flaking tools seems to be a common practise. 
Flaking activities are predominant at both sites, and include bipolar knapping as well

428 as freehand flaking (de la Torre and Mora, submitted ' $a$ ' and ' $b$ '). The bipolar technique is more common at HWK EE, where 74 bipolar cores $(8.0 \%$ of all cores from the T1-Main Trench, T27, T28 and T29 trenches) were identified, while at EF-HR (T2-Min Trench and T12) $5.2 \%$ of cores $(n=9)$ were bipolar (Table 7).

Pitted stones were described previously at Olduvai, primarily from Beds III and IV (Leakey and Roe, 1994), and more rarely from Beds I and II (Leakey, 1971). These objects have been linked to bipolar knapping (Jones, 1994), and experimental work has shown that cobbles used as passive and active elements can develop depressions on their surfaces (Le Brun-Ricalens et al., 1989; Jones, 1994; Roda et al., 2012). It was not possible to assess with confidence whether the pitted stones from HWK EE and EF-HR were used as active or passive elements, as most were of a size suitable for both motions. Whichever the case, most of the HWK EE and EF-HR pitted stones can be considered as part of a bipolar chaîne opératoire, due to the characteristics of depressions which have developed through a process of repetitive impact in which the surface is fractured, producing the detachment of small fragments, and progressively forms a depression with an irregular internal surface. These features, as well as the presence of bipolar cores and pieces esquilles in the lithic assemblages, suggest that most pitted stones from HWK EE and EF-HR were involved in bipolar knapping activities.

Experimental bipolar anvils of Olduvai quartzite usually do not develop depressions, and they show instead large and clustered crushed areas (de la Torre et al., 2013). Such wear patterns have not been identified conclusively on any of the analysed percussive tools, suggesting that both HWK EE and EF-HR hominins chose preferentially lava cobbles as anvils (i.e. some of the pitted stones) to be used on bipolar knapping activities. 
Blumenschine and Selvaggio, 1988; Blumenschine, 1995). Bone specimens with percussive

traces and notches have been identified at both EF-HR (de la Torre et al., submitted 'b') and,

broke limb bones to access the marrow (Pante et al., submitted). In this regard, it has been

suggested elsewhere (Mora and de la Torre, 2005) that anvils (which were identified only at

HWK EE), and probably other tools such as HFA, could have been involved in bone breaking.

Experiments have shown that bone marrow extraction is an activity during which the use-wear formation process is very slow, and other percussive activities (such as nut cracking or plant pounding) can produce similar use-wear patterns (de la Torre et al., 2013; Sánchez Yustos et al., 2015). Experimental anvils occasionally have fragments detached, and bear scattered impacts produced by missed blows, microscopic abrasions (made by the movement of the bone across their surface), and small removals along the edges (de la Torre et al., 2013, Benito-Calvo et al., in press). Hammerstones used to break bones show grain and crystal crushing on their surfaces, with sporadic detachment of small fragments and grains. Damage becomes more intense on those hammerstones used for longer period (Benito-Calvo et al., in press). Micro 3D techniques have shown that use-wear marks on tools used for breaking bones are mainly recognised at a microscopic level, rather than macroscopically. This is because bones absorb force transmitted by the hammer, which is thus barely transferred to the anvil. Therefore, bone-breaking tools may go undetected in the archaeological record unless a microscopic approach is adopted (Benito-Calvo et al., in press). been identified in the ESA record through functional analysis on flakes (e.g. Lemorini et al., 
carcasses (Pante et al., submitted), and in EF-HR the same pattern probably applies (de la

478 Torre et al., submitted 'b'). However, the identification of these activities through the analysis of archaeological pounding tools is uncertain. Experimental anvils used to process tubers and tenderize meat show impact points and crushed areas scattered across the anvil surfaces (de la Torre et al., 2013).

Nut-cracking activities are known in the ESA (Goren-Inbar et al., 2002; 2014; 2015), but its identification is generally elusive in most of the archaeological record. Experimental anvils used for nut cracking by humans show a very low degree of surface modification, with only few isolated impact points and shallow abrasions identified microscopically (de la Torre et al., 2013). Experimental anvils of Olduvai quartzite used by chimpanzees (Pan troglodytes) in nut cracking (Arroyo et al., 2016) also show a low degree of modification, with occasional detachment of fragments from tools' edges. Use-wear marks in active and passive elements are characterised by small crushed areas and impact points located mainly on peripheral areas of the working surfaces. This use-wear pattern has been interpreted as the result of the contact between the active and the passive elements (Arroyo et al., 2016). Overall, quartzite nut cracking tools used by captive chimpanzees show similar use-wear traces (small area of coverage, similar distribution patterns) to anvils used for plant processing or bone breaking (Arroyo et al., 2016). Such similarities of use-wear patterns on tools involved in different tasks are connected with the adoption of a thrusting percussion motion in all these tasks, and the resistant properties of quartzite, and therefore contribute to

497 further complicate the functional attribution of EF-HR and HWK EE pounding tools.

As a whole, wear formation on pounding tools used to process organic materials is 499 dependent on the length of the activity, the hardness of the material process, and the intensity 500 of the contact between the active and the passive elements. This latter process (i.e. contact 501 between the hammer and the anvil) is responsible for most of wear traces observed on the 
experimental tools. Only microscopic abrasions identified on some anvils used to break bones and crack nuts are the result of a friction motion against the materials during the activity. In addition, similarities on use-wear patterns on tools employed on different activities are caused by to the use of similar kinetic motions.

Reconstructing percussive activities by hominins: a comparison of experimental and

archaeological pounding tools

It is relevant to acknowledge that a correlation of bone breaking or plant processing

with a particular type of pounding tool is uncertain. However some patterns can be recognised on both the archaeological and the experimental assemblages.

Quartzite HAE and utilised materials from HWK EE with low intensity wear traces implying contact with a medium-low resistant material can be added to anvils as tools potentially used for processing bones and/or other organic materials. This is suggested by microscopic analysis which revealed use-wear traces such as impacts, step fractures or pits associated with a thrusting percussion motion, and having similar morphologies to those traces seen on experimental tools (de la Torre et al., 2013; Arroyo et al., 2016). Further

517 similarities are evident on other anvils from Bed I and II Leakey's assemblages, which show working surfaces are dominated by scattered impact points, stepped fractures, abrasions, and crushed crystals (Arroyo and de la Torre, 2016). Such consistent use-wear patterns on the anvils help to speculate on their potential use on similar activities across Beds I and II.

HFA have been recognised in other ESA sites such as Gadeb (de la Torre, 2011),

522 Garba IVD (Gallotti, 2013) and Gesher Benot Ya'aqov (Alperson-Afil and Goren-Inbar, 2016). All of them are very similar despite their chronological and geographic variability. Assessing their function is problematic as experimental active pounding elements do not display similar use-wear patterns as those seen on archaeological pieces. The latter show intense percussive traces and have multiple fractures indicating potential involvement in 
heavy duty tasks in which they were in contact with high resistant materials. The presence of subspheroids/spheroids in HWK EE is a further difference with EFHR, where there are none. Leakey (1971) noted that the presence of these tools increased in Middle and Upper Bed II, and considered them to be the benchmark of the Developed Oldowan. Morphological characteristics of subspheroids/spheroids have been widely 532 discussed in the literature, with some supporting a preconceived spherical shape (Texier and Roche, 1995), while others have considered their final shape as the result of intense use (e.g. Schick and Toth, 1994). Subspheroids/spheriods have been interpreted as throwing implements (Leakey, 1931; 1950; Clark, 1955; Leakey, 1971; Wilson et al., 2016), knapping hammerstones (Willoughby, 1987; Schick and Toth, 1994), cores with subsequent battering

537 (Mora and de la Torre, 2005), and active elements for the processing of plants (Willoughby, 1985; Sánchez Yustos et al., 2015). At HWK EE, flaking scars clearly link subspheroids with knapping activities (Figure 6B), while the superficial incidence of percussive marks (Figure 6A) suggests additional use in non-invasive activities (e.g. contact with materials of medium541 low resistance, or limited use).

All things considered, use-wear patterns on pounded tool from HWK EE and EF-HR suggest that hominins primarily used them in a direct percussion motion. Percussive tools involved on knapping activities (hammerstones, pitted stones and some re-used cores) are predominant on both sites. The low incidence of use-wear traces on tool types such as HAE, anvils and subspheroids, reinforce their use on non-flaking activities to process medium-soft

547 materials which included limb bones, but probably plants and/or nuts as well. In this regard, while acquisition of meat is often invoked as the main objective of Plio-Pleistocene subsistence strategies (e.g., Plummer, 2004), the limited number of studies on use wear analysis (e.g. Keeley and Toth, 1981; Sussman, 1987; Lemorini et al., 2014) are pointing to other functions for the early stone tools, and a wide breadth of the hominin diet. Nevertheless, 
establishing which specific organic materials beside bones were processed through pounding activities at Olduvai Gorge will require further research, and the aid of other techniques such as residue analysis.

\subsection{The HWK EE and EF-HR percussive assemblages in the wider context}

Absolute frequencies of pounding tools from Olduvai Middle and Upper Bed II assemblages (Table 10) indicate variable proportions, irrespective of whether they are Acheulean or Oldowan. Figure 11 suggests association of some sites with particular tool types, such as hammerstones at HWK EE (Leakey and OGAP), EF-HR and FC West, or spheroids/subspheroids at BK and HWK E.

\section{Insert Table 10}

Insert Figure 11

Overall, there seems to be no dichotomy at Olduvai between the Acheulean and Oldowan on the frequencies of pounding tools. Rather than cultural, differences must be function-related, and therefore each locality should be considered individually. There is a greater variety of pounding tools (e.g. HAE) which might have not been used for stone knapping activities at HWK EE, while at EF-HR percussive tools related to flake and LCT production predominate. In other Acheulean localities such as TK, there is a large collection of percussive objects with anvils and spheroids/subspheroids (Leakey, 1971; de la Torre and Mora, 2005), although recent excavations have documented lower frequencies of both types of percussive tools (Santonja et al., 2014). Pounding tools have also been recognised in other East African ESA sites of a similar chronological range as EF-HR and HWK EE. Such is the case at Koobi Fora (Isaac, 1997), Garba IV (Gallotti, 2013), and Gadeb 2E (de la Torre, 2011) among others, although percussive objects rarely represent more than $5 \%$ of the entire 
lithic assemblages.

578

579

\section{Conclusions}

580

Recent excavations at EF-HR and HWK EE produced a large collection of tools involved in percussive activities which have been macro- and microscopically analysed in this paper. We have shown that hominins adjusted selection of hammerstones according to different knapping activities, with the larger hammerstones used at EF-HR related primarily to the production of large cutting tools. Documentation of hammerstones reused as cores, subspheroids resulting from a combination of flaking and battering tasks, and pitted stones with occasional flaking scars, reinforce the poly-functional nature of Early Stone Age tools.

The results presented in this paper highlight the importance of applying use wear analysis to percussive tools as means to interpret hominin subsistence activities. Our microscopic analysis shows variability in the intensity of use that could be linked to the processing of different materials. The larger collection and variety of pounding tools found at HWK EE reveals a wider range of activities, probably involved in bone breaking, bipolar knapping and possibly the processing of other organic materials, while at EF-HR the focus is primarily focused on the production of stone tools. The data presented here suggests interassemblage variability in pounding assemblages, a variability that includes the existence of specific points in the landscape which early humans dedicated to particular tasks.

\section{Acknowledgments}

We thank the OGAP team members involved in field and laboratory work, and Norah Moloney, the anonymous reviewers and the editors for their comments. Excavations were

600 authorized by the Tanzania Commission for Science and Technology (COSTECH), the 601 Department of Antiquities, and the Ngorongoro Conservation Area Authority. Funding by the 
602 European Research Council-Starting Grants (283366) and the Leverhulme Trust (IN-052) is 603 acknowledged.

604

\section{Bibliography}

606

607 Adams, J., 1993. Mechanisms of wear on ground stone surfaces. Pacific Coast 608 Archaeological Society Quarterly 29, 61-74.

609

Adams, J., 2002. Mechanisms of wear on ground stone surfaces, in: Procopiu, H., Treuil, R. (Eds.). Moudre et broyer: L'interprétation fonctionelle de l'outillage de mouture et de broyage dans la Préhistoire et l'Antiquité. CTHS, pp. 57-68.

Adams, J., Delgado, S., Dubreuil, L., Hamon, C., Plisson, H., Risch, R., 2009. Functional analysis of macro-lithic artefacts: a focus on working surfaces, in: Costa, L.J.,

Alperson-Afil, N., Goren-Inbar, N., 2016. Scarce but significant: the limestone component of the Acheulean site of Gesher Benot Ya'aqov, Israel, in: Haidle, M.N., Conard, N.J., Bolus, M. (Eds.). The nature of culture: base on an interdisciplinary symposium 'The nature of Culture', Tübingen, Germany. Springer, pp. 41-56.

Arroyo, A., Hirata, S., Matsuzawa, T., Torre, I. de la, 2016. Nut cracking tools used by captive chimpanzees (Pan troglodytes) and their comparison with Early Stone Age percussive artefacts from Olduvai Gorge. Plos One 11, e0166788. doi: 10.1371/journal.pone.0166788

Arroyo, A., Torre, I. de la, 2016. Assessing the function of pounding tools in the Early Stone 626 Age: a microscopic approach to the analysis of percussive artefacts from Beds I and 
Asryan, L., Ollé, A., Moloney, N., King, T., Murray, J., 2017. Chemical alteration of lithic artefacts: an experimental case study on the effect of guano on stone flakes and its contextualization in the archaeological assemblage of Azokh Cave (Southern Cuacasus). Archaeometry. Doi: 10.1111/arcm.12300

633

Benito-Calvo, A., Arroyo, A., Sánchez-Romero, L., Pante, M., Torre, I. de la, in press. Quantifying 3D micro-surface changes on experimental stones used to break bones

Blumenschine, R.J., 1995. Percussion marks, tooth marks, and experimental determinations of the timing of hominid and carnivore access to long bones at FLK Zinjanthropus, Olduvai Gorge, Tanzania. Journal of Human Evolution 29, 21-51.

644

Blumenschine, R.J., Selvaggio, M.M., 1988. Percussion marks on bone surfaces as a new

Bunn, H.T., 1981. Archaeological evidence for meat-eating by Plio-Pleistocene hominids diagnostic of hominid behaviour. Nature 333, 763-765. from Koobi Fora and Olduvai Gorge. Nature 291, 547-577.

Carmody, R., Wrangham, R.W., 2009. The energetic significance of cooking. Journal of Human Evolution 57, 379-391. R., Harris, J.W.K., 2014. Quantifying traces of tool use: A novel morphometric analysis of damage patterns on percussive tools. Plos One 9, e113856. doi: 
653 Chavaillon, J., 1979. Essai pour une typologie du matériel de percussion. Bulletin de la 654 Societé Préhistorique Française 76, 230-233.

655

Chavaillon, J., 2004. The site of Gombore I. Discovery, geological introduction and study of percussion material and tools on pebble, in: Chavaillon, J., Piperno, M. (Eds.). Studies on the Early Paleolithic site of Melka Kunture, Ethiopia. Istituto italiano di preistoria e protostoria, Florence, pp. 253-369.

Clark, J.D., 1955. The stone ball: its associations and use by prehistoric man in Africa, in: Balout, L. (Ed.). Congrés Panafricain de Préhistoire. Actes de la II session. Alger, 1952. Arts et métiers graphiques, Paris, pp. 403-416.

Delagnes, A., Roche, H., 2005. Late Pliocene hominid knapping skills: the case of Lokalalei 2C, West Turkana, Kenya. Journal of Human Evolution 48, 435-472.

Dubreuil, L., 2001. Functional studies of prehistoric grindingstones: a methodological research. Bulletin du CRFJ 9, 73-87.

Dubreuil, L., 2004. Long-term trends in Natufian subsistence: a use-wear analysis of ground stone tools. Journal of Archaeological Science 31, 1613-1629.

Ferraro, J.V., Plummer, T.W., Pobiner, B.L., Oliver, J.S., Bishop, L.C., Braun, D.F., Ditchfield, P.W., Seaman III, J.W., Binetti, K.M., W., S.J.J., Hertel, F., Potts, R., 2013. Earliest archaeological evidence of persistent hominin carnivory. Plos One 8, e62174. doi:10.1371/journal.pone.0062174

Gallotti, R., 2013. An older origin for the Acheulean at Melka Kunture (Upper Awash, Ethiopia): Techno-economic behaviours at Garba IVD. Journal of Human Evolution $65,594-620$.

Gobert, E., 1910. Balles polyédriques à facettes convexes du Paléolithique nord-africain. Bulletin de la Societé Préhistorique Française 7, 417-419. 
677 Goren-Inbar, N., Melamed, Y., Zohar, I., Akhilesh, K., Pappu, S., 2014. Beneath Still Waters

678

679

680

681

682

683

684

685

686

687

688

689

690

691

692

693

694

695

696

697

698

699

700

701 - Multistage Aquatic Exploitation of Euryale ferox (Salisb.) during the Acheulian, in: Fernandes, R., Meadows, J. (Eds.). Human exploitation of aquatic landscapes special issue. Internet Archaeology.

Goren-Inbar, N., Sharon, G., Alperson-Afil, N., Herzlinger, G., 2015. A new type of anvil in the Acheulian of Gesher Benot Ya'aqov, Israel. Philosophical Transactions of the Royal Society of London B: Biological Sciences 370.

Goren-Inbar, N., Sharon, G., Melamed, Y., Kislev, M.E., 2002. Nuts, nut cracking, and pitted stones at Gesher Benot Ya'aqov, Israel. Proceedings of the National Academy of Sciences of the United States of America 99, 2455-2460.

Hammer, Ø., Harper, D.A.T., Ryan, P.D., 2001. PAST: Paleontological statistics software package for education and data analysis. Palaeontologia Electronica 4, 9. http://palaeo-electronica.org/2001_1/past/issue1_01.htm.

Hamon, C., 2008. Functional analysis of stone grinding and polishing tools from the earliest Neolithic of north-western Europe. Journal of Archaeological Science 35, 1502-1520.

Isaac, G.L., 1997. Plio-Pleistocene archaeology. Koobi Fora Research Project. Volume 5. Clarendon Press, Oxford.

Jones, P.R., 1994. Results of experimental work in relation to the stone industries of Olduvai Gorge, in: Leakey, M.D., Roe, D.A. (Eds.). Olduvai Gorge. Excavations in Beds III, IV and the Masked Beds, 1968-1971. Cambridge University Press, Cambridge, pp. 254-298.

Kato, K., 2002. Classification of wear mechanisms/models. Journal of Engineering Tribology 216, 349-355.

Keeley, L.H., 1980. Experimental determination of stone tool uses: a microwear analysis. University of Chicago Press, Chicago. 
Keeley, L.H., Toth, N., 1981. Microwear polishes on early stone tools from Koobi Fora, Kenya. Nature 293, 464-465.

704

705

706

707

708

709

710

Le Brun-Ricalens, F., 1989. Contribution à l'étude des pièces esquillées: la présence de percuteurs à "cupules". Bulletin de la Societé Préhistorique Française 86, 194-211.

Leakey, L.S.B., 1931. The Stone Age cultures of Kenya colony. Cambridge University Press, Cambridge.

Leakey, L.S.B., 1950. Stone implements: how they were made and used. The South African Archaeological Bulletin 5, 71-74.

Leakey, M.D., 1971. Olduvai Gorge, Vol. 3. Excavations in Beds I and II, 1960-1963. Cambridge University Press, Cambridge.

Leakey, M.D., Roe, D.A., 1994. Olduvai Gorge. Vol. 5. Excavations in Beds III, IV and the Masek Beds, 1968-1971. Cambridge University Press, Cambridge.

Lemorini, C., Plummer, T., W., Braun, D.F., Crittenden, A.N., Ditchfield, P.W., Bishop, L., C., Hertel, F., Oliver, J.S., Marlowe, F.W., Schoeninger, M.J., Potts, R., 2014. Old stones' song: use-wear experiments and analysis of the Oldowan quartz and quartzite assemblage from Kanjera South (Kenya). Journal of Human Evolution 70, 10-25.

Manega, P., 1993. Geochronology, geochemistry and isotopic study of the Plio-Pleistocene hominid sites and the Ngorongoro volcanic highland in Northern Tanzania. University of Chicago, Boulder. Unpublished PhD.

McHenry, L., submitted. Tephrochronology of Bed II, Olduvai Gorge, Tanzania, and the chronology of the Oldowan-Acheulean transition. Journal of Human Evolution.

McHenry, L., Torre, I. de la, submitted. Hominin raw material procurement in the OldowanAcheulean transition at Olduvai Gorge. Journal of Human Evolution.

Melamed, Y., Kislev, M.E., Geffen, E., Lev-Yadun, S., Goren-Inbar, N., 2016. The plant component of an Acheulian diet at Gesher Benot Ya'aqov, Israel. PNAS, 1-6. doi: 
728

729

730

731

732

733

734

735

736

737

738

739

740

741

742

743

744

745

746

747

748

749

750

Mora, R., Torre, I. de la, 2005. Percussion tools in Olduvai Beds I and II (Tanzania): Implications for early human activities. Journal of Anthropological Archaeology 24, 179-192.

Murray, S.S., Schoeninger, M.J., Bunn, H.T., Pickering, T.R., Marlett, J.A., 2001. Nutritional composition of some wild plant foods and honey used by Hadza foragers of Tanzania. Journal of Food Composition and Analysis 14, 3-13.

Odell, G.H., 1979. A new and improved system for the retrieval of functional information from microscopic observations of chipped stone tools, in: Hayden, B. (Ed.), Lithic Use-Wear Analysis, Academic Press, New York, pp. 329-344.

Olson, E., 2011. Particle shape factors and their use in image analysis-Part 1: theory. Journal of GXP Compliance 15, 85-95.

Pante, M., Njau, J.K., Hensley-Marchand, B., Keevil, T.L., Martín-Ramos, C., Franco Peters, R., Torre, I. de la, submitted. The carnivorous feeding behavior of early Homo at HWK EE, Bed II, Olduvai Gorge, Tanzania. Journal of Human Evolution.

Pante, M., Torre I. de la, submitted. A hidden treasure of the Lower Pleistocene: The Leakey HWK EE assemblage. Journal of Human Evolution.

Peters, C.R., 1987. Nut-Like oil seeds: Food for monkeys, chimpanzees, humans, and probably ape-men. American Journal of Physical Anthropology 73, 333-363.

Piperno, M., Bulgarelli, G.M., Gallotti, R., 2004. The site of Garba IV. The lithic industry of Level D. Tools on pebble and percussion material, in: Chavaillon, J., Piperno, M. (Eds.). Studies on the Early Paleolithic site of Melka Kunture. Ethiopia. Istituto italiano di preistoria e protostoria, Sapienza, pp. 545-580.

Plummer, T.W., 2004. Flaked stones and old bones: biological and cultural evolution at the dawn of technology. Yearbook of Physical Anthropology 47, 118-164. 
Pobiner, B.L., 2007. Hominin-carnivore interactions: evidence from modern carnivore bone modification and Early Pleistocene archaeofaunas (Koobi Fora, Kenya; Olduvai Gorge, Tanzania). Rutgers University.

Pobiner, B.L., Rogers, M.J., Monahan, C.M., Harris, J.W.K., 2008. New evidence for hominin carcass processing strategies at 1.5 Ma, Koobi Fora, Kenya. Journal of Human Evolution 55, 103-130.

Rasband, W.S., 1997. ImageJ. U. S. National Institutes of Health, Bethesda, Maryland, USA, 2014. http://imagej.nih.gov/ij/.

Roda Gilabert, X., Martínez-Moreno, J., Mora, R., 2012. Pitted stone cobbles in the Mesolithic site of Font del Ros (Southeastern Pre-Pyrenees, Spain): some experimental remarks around a controversial tool type. Journal of Archaeological Science 39, 1587-1598.

Sánchez Yustos, P., Diez-Martín, F., Díaz, I. M., Duque, J., Fraile, C., Domínguez, M., 2015. Production and use of percussive stone tools in the Early Stone Age: Experimental approach to the lithic record of Olduvai Gorge, Tanzania. Journal of Archaeological Science: Reports 2, 367-383.

Santonja, M., Panera, J., Rubio-Jara, S., Pérez-González, A., Uribelarrea, D., DomínguezRodrigo, M., Mabulla, A.Z.P., Bunn, H.T., Baquedano, E., 2014. Technological strategies and the economy of raw materials in the TK (Thiongo Korongo) lower occupation, Bed II, Olduvai Gorge, Tanzania. Quaternary International 322-323, 181208.

Schick, K.D., Toth, N., 1994. Early Stone Age technology in Africa. A review and case study into the nature and function of spheroids and subspheroids, in: Curroccini, R.S., Ciochon, R.L. (Eds.). Integrative paths to the past. Paleoanthropological advances in honor of F. Clark Howell. Prentice-Hall, Inc., New Jersey, pp. 429-449. 
Semenov, S.A., 1964. Prehistoric technology: an experimental study of the oldest tools and artefacts from traces of manufacture and wear Redwood Press Limited, Great Britain.

Sussman, C., 1987. Résultats d'une étude de microtraces d'usure sur un echantillon d'artefacts d'Olduvai. L'Anthropologie 91, 375-380.

Tanabata, T., Shibaya, T., Hori, K., Ebana, K., Yano, M., 2012. SmartGrain: high-throughput phenotyping software for measuring seed shape through image analysis. Plant Physiology 160, 1871-1880.

Texier, P.-J., Roche, H., 1995. Polyèdre, sub-sphéroïde, sphéroïde et bola: des segments plus ou moins longs d’une même chaîne opératoire. Cahier Noir 7, 31-40.

Torre, I. de la, 2011. The Early Stone Age lithic assemblages of Gadeb (Ethiopia) and the Developed Oldowan/early Acheulean in East Africa. Journal of Human Evolution 60, 768-812.

Torre, I. de la, Albert, R.M., Arroyo, A., Macphail, R., McHenry, L., Mora, R., Njau, J.K., Pante, M., Rivera-Rondón, C.A., Rodríguez-Cintas, Á., Stanistreet, I., Stollhofen, H., Wehr, K., submitted 'a'. New excavations at the HWK EE site: archaeology, palaeoenvironment and site formation processes during late Oldowan times at Olduvai Gorge, Tanzania. Journal of Human Evolution.

Torre, I. de la, Albert, R.M., Macphail, R., McHenry, L., Pante, M., Rodríguez-Cintas, Á., Stanistreet, I., Stollhofen, H., submitted 'b'. The contexts and early Acheulean archaeology of the EF-HR palaeolandscape (Olduvai Gorge, Tanzania). Journal of Human Evolution.

Torre, I. de la, Benito-Calvo, A., Arroyo, A., Zupancich, A., Proffitt, T., 2013. Experimental protocols for the study of battered stone anvils from Olduvai Gorge (Tanzania). Journal of Archaeological Science 40, 313-332.

Torre, I. de la, Mora, R., submitted 'a'. Oldowan technological behaviour at Olduvai Gorge, 
Torre, I. de la, Mora, R., submitted 'b'. The EF-HR stone tool assemblage and its implications for the emergence of the Acheulean in East Africa. Journal of Human Evolution.

Tringham, R., Cooper, G., Odell, G.H., Voytek, B., Whitman, A., 1974. Experimentation in the formation of edge-damage: a new approach to lithic analysis, Journal of Field Archaeology 1, 171-196.

Van Gijn, A.L., 1990. Post-depositional surface modifications. Analecta Praehistorica Leidensia 22, 51-58.

Willoughby, P.R., 1985. Spheroids and battered stones in the African Early Stone Age. World Archaeology 17, 44-60.

Willoughby, P.R., 1987. Spheroids and battered stones in the African early and middle Stone Age. Cambridge monographs in African archaeology, Cambridge.

814 Wilson, A.D., Zhu, Q., Barham, L., Stanistreet, I., Bingham, G.P., 2016. A dynamical analysis of the suitability of prehistoric spheroids from the Cave of Hearths as thrown projectiles. Scientific Reports 6.

817 Yamakoshi, G., 1998. Dietary responses to fruit scarcity of wild chimpanzees at Bossou, Guinea: possible implications for ecological importance of tool use. American Journal of Physical Anthropology 106, 283-295.

\section{List of Tables}

822 Table 1. Percussive objects from HWK EE and EF-HR (see Table 2 for brief descriptions of 823 each pounding tool).

824 Table 2. Pounding tool classification.

825 Table 3. General dimensions ( $\mathrm{mm}$ ) and weight (gr) of percussive objects from EF-HR and 826 HWK EE. 
Table 4. Raw materials of percussive tools.

Table 5. Pounding tool blanks from HWK EE and EF-HR.

Table 6. Shape analysis of quartzite subspheroids and hammerstones with fracture angles

830 from HWK EE.

831 Table 7. Absolute frequencies of bipolar cores, cores, flake fragments, chunks with 832 percussive marks.

833 Table 8. Raw materials of pounding tools analysed microscopically. Abbreviations: Qtz: 834 quartzite; Ba: Basalt; Ph: phonolite; Pu: pumice; T/Tr: trachyte/trachyandesite; Gn: gneiss.

835 Table 9. Microscopic traces on pounding tools from HWK EE and EF-HR.

836 Table 10. Absolute frequencies of pounding tools from Middle and Upper Bed II sites at

837 Olduvai Gorge. *The lack of hammerstones at SHK is because Mary Leakey discarded all 838 cobbles during archaeological work. **These objects were included as 'other pounded 839 pieces' in the original publication. Abbreviations: HAE: hammerstones with active edge; 840 HFA: hammerstones with fracture angles.

\section{List of Figures}

843 Figure 1. Box plots with dimensions (A-C) and weight (D) of each category of pounding tool 844 from HWK EE and EF-HR.

845 Figure 2. Regression line scatter plots and principal component analysis (PCA) comparing 846 HWK EE and EF-HR percussive objects. A) All pounding tools (HWK EE, R ${ }^{2}=0.674$; EF847 HR, $\mathrm{R}^{2}=0.798$ ); B) PCA including length, width, thickness and weight of HWK EE and EF848 HR percussive tools (Line legend: black: knapping hammerstones; blue: HFA; red: HAE; 849 pink: pitted stone; green: utilised material; purple: subspheroids; dark blue: anvils). C) 850 Knapping hammerstones (HWK EE, $\mathrm{R}^{2}=0.642$; EF-HR, $\mathrm{R}^{2}=0.866$ ); D) HAE (HWK EE, 851 $\left.\left.\left.\mathrm{R}^{2}=0.530 ; \mathrm{EF}-\mathrm{HR}, \mathrm{R}^{2}=0.912\right) ; \mathrm{E}\right) \mathrm{HFA}\left(\mathrm{HWK} \mathrm{EE}, \mathrm{R}^{2}=0.849 ; \mathrm{EF}-\mathrm{HR}, \mathrm{R}^{2}=0.664\right) ; \mathrm{F}\right)$ 
852 Pitted stones (HWK EE, $\left.\mathrm{R}^{2}=0.311 ; \mathrm{EF}-\mathrm{HR}, \mathrm{R}^{2}=1\right)$.

853 Figure 3. Knapping hammerstones from HWK EE (A) and example of a hammerstone linked to LCT production from EF-HR (B). All objects are at the same scale. Note the intense battered areas associated with large fractures, and larger area covered on hammerstones from

856 EF-HR. Yellow arrows indicate direction of battered fractures. Yellow circles in A) indicate areas of battering.

Figure 4. HAE from HWK EE. A) Quartzite HAE with superficial battered marks on an angular area; B) HAE on a trachyte/trachyandesite cobble with battered marks associated with multiple macrofractures (see 3D model in SOM 2).

861 Figure 5. Subspheroids and HFA from HWK EE. Yellow arrows indicate direction of 862 battering.

863 Figure 6. A) Subspheroid (HWKEE LCHA-1081) with multifacial flaking exploitation 864 (represented by red arrows) and percussive marks are associated with macrofractures (yellow 865 arrows). 1.- Detail of crystal crushing caused by a direct impact (20x, scale $2 \mathrm{~mm})$. B) 866 Subspheroid (HWKEE L1-2540) with isolated flaking scars and large battered areas on both 867 ends of the blank and divergent macrofractures (arrow colour pattern is the same as B). Figure 7. Pitted stones from EF-HR (A) and HWK EE (T27 L32-23 (B) and HWKEE L101697 (C)). Microscopic detail of the inner part of the depression (B-1) at 10x (scale $3 \mathrm{~mm}$ ).

870 Yellow arrow in C) indicates direction of a battered scar, while red arrows indicate flaking scars. (See SOM 4 for 3D models of HWK EE pitted stones).

872 Figure 8. Use-wear patterns in HWK EE anvils: A) T29L52-83 bears impact points on the 873 central area of the horizontal plane. 1.-Impact point associated with an irregular micro874 fracture $(40 x$, scale $700 \mu \mathrm{m})$; 2.-Cicular impact point $(40 \mathrm{x}$, scale $700 \mu \mathrm{m})$. B) Artefact 875 T29L51-264 shows a small crushed area located on the edge. C) Anvil T28L40-1 with 876 stepped edge fractures. 1.-Detail of crystal fracture (10x, scale $3 \mathrm{~mm})$; 2.-Crystal crushing 
877 (10x, scale $3 \mathrm{~mm})$.

878 Figure 9. Microwear traces on percussive tools. A) Quartzite anvil (HWKEE L1-3752)

879 bearing linear traces on the horizontal plane (1. 10x, scale $3 \mathrm{~mm}$ ) and a deep crushed area on 880 a lateral plane (2. 10x, scale $3 \mathrm{~mm}$ ). B) Quartzite HAE (HWKEE L10-1760) with crushing on 881 one edge associated with multiple stepped micro-fractures and slight edge rounding (1 and 2. 882 Both details at 10x, scales $3 \mathrm{~mm}$ ).

883 Figure 10. Microwear traces of a Trachyte/trachyandesite hammerstone (EF-HR L2-1145) 884 from EF-HR bearing grain crushing (1. 30x, scale $1 \mathrm{~mm} ; 2.50 x$, scale $800 \mu \mathrm{m})$ and impact 885 points (3.20x, scale $2 \mathrm{~mm})$. Yellow arrows refer to battered scars.

886 Figure 11. Correspondence factorial analysis (CFA) of percussive tools per Middle/Upper 887 Bed II sites (see details in Table 9). Sph/Sub-sph: spheroids and subspheroids. SHK have 888 been excluded as Mary Leakey did not collect any hammerstones.

889

890 Supplementary Online Material

891 SOM 1. Absolute and relative frequencies of percussive objects across different stratigraphic 892 intervals at HWK EE (A), and the geological context of pounded tools from EF-HR (B).

893 SOM 2. 3D model of the HAE from Figure 4B.

894 SOM 3. 3D model of a pitted stone (HWKEE L6-981) with a single angular depression and 895 polished inner surface.

896 SOM 4. 3D models of the pitted stone from Figure 7B and object T29L50-89. Both objects 897 are poly-functional tools, as they show battering marks and flaking scars. 
Table 1

\begin{tabular}{|c|c|c|c|c|}
\hline & \multicolumn{2}{|c|}{ EF-HR } & \multicolumn{2}{|c|}{ HWK EE } \\
\hline & $\mathbf{N}$ & $\%$ & $\mathbf{N}$ & $\%$ \\
\hline Battered fragments & 0 & 0 & 19 & 5.4 \\
\hline Fractured knapping hammerstones & 8 & 16.0 & 123 & 35.2 \\
\hline Knapping hammerstones & 30 & 60.0 & 119 & 34.1 \\
\hline Hammerstones with active edge & 3 & 6.0 & 20 & 5.7 \\
\hline Hammerstones with fracture angles & 7 & 14.0 & 19 & 5.4 \\
\hline Subspheroids & 0 & 0.0 & 12 & 3.4 \\
\hline Utilised material & 0 & 0.0 & 7 & 2.0 \\
\hline Pitted stones & 2 & 4.0 & 19 & 5.4 \\
\hline Passive hammer with friction marks & 0 & 0.0 & 2 & 0.6 \\
\hline Anvils & 0 & 0.0 & 9 & 2.6 \\
\hline Total & $\mathbf{5 0}$ & 100 & 349 & 100 \\
\hline
\end{tabular}




\begin{tabular}{|c|c|c|c|c|}
\hline Function & Technological category & Abbreviation & Characteristics & Reference \\
\hline \multirow{5}{*}{ Active elements } & Knapping hammerstone & & $\begin{array}{l}\text { Concentrated battered areas and } \\
\text { impact points located on convex } \\
\text { surfaces, occasionally linked to } \\
\text { fractures with an oval/circular } \\
\text { morphology }\end{array}$ & Leakey, 1971 \\
\hline & Hammerstone with fracture angles & HFA & $\begin{array}{l}\text { Battered areas associated to multiple } \\
\text { angular and dihedral fractures, with no } \\
\text { directionality of the detachments, and } \\
\text { opposed to an unmodified surface }\end{array}$ & Mora and de la Torre, 2005 \\
\hline & Hammerstone with active edge & HAE & $\begin{array}{l}\text { Battering on a natural angular surface } \\
\text { associated to multiple non-invasive } \\
\text { fractures }\end{array}$ & This work \\
\hline & Spheroids/subspheroid & & $\begin{array}{l}\text { Tools with a spherical shape, faceted } \\
\text { scars and battered areas or impact } \\
\text { points located mainly on the ridges }\end{array}$ & Leakey, 1971 \\
\hline & Utilised material & & $\begin{array}{l}\text { Isolated impact marks scattered across } \\
\text { the surfaces of the blank an a } \\
\text { superficial incidence }\end{array}$ & This work \\
\hline Active/passive elements & Pitted Stone & & $\begin{array}{l}\text { Oblong/oval depressions on one or } \\
\text { more surfaces of the artefact }\end{array}$ & Leakey, 1994 \\
\hline \multirow{2}{*}{ Passive elements } & Anvil & & $\begin{array}{l}\text { Cuboid blocks or cobblestones with } \\
90^{\circ} \text { edges bearing percussive marks } \\
\text { and plunging scars }\end{array}$ & Leakey, 1971 \\
\hline & $\begin{array}{l}\text { Passive hammer with friction } \\
\text { marks }\end{array}$ & PHFM & $\begin{array}{l}\text { Tools whose working areas show } \\
\text { traces produced by a friction motion }\end{array}$ & This work \\
\hline
\end{tabular}


Table 3

\begin{tabular}{|c|c|c|c|c|c|c|c|c|c|c|c|}
\hline & & \multicolumn{5}{|c|}{ EF-HR } & \multicolumn{5}{|c|}{ HWK EE } \\
\hline & & $\mathbf{N}$ & Maximum & Minimum & Mean & $\begin{array}{l}\text { Std. } \\
\text { Dev. }\end{array}$ & $\mathbf{N}$ & Maximum & Minimum & Mean & $\begin{array}{l}\text { Std. } \\
\text { Dev. }\end{array}$ \\
\hline \multirow{4}{*}{$\begin{array}{c}\text { Fractured } \\
\text { hammerstones }\end{array}$} & Length & \multirow{4}{*}{8} & 102 & 43 & 80,4 & 19,0 & \multirow{4}{*}{123} & 103 & 15 & 68,3 & 16,5 \\
\hline & Width & & 80 & 37 & 61,3 & 15,6 & & 85 & 10 & 54,8 & 13,8 \\
\hline & Thickness & & 77 & 23 & 45,0 & 16,4 & & 72 & 7 & 41,4 & 12,2 \\
\hline & Weight & & 790,0 & 67,1 & 301,3 & 227,1 & & 867,2 & 10,0 & 222,0 & 141,1 \\
\hline \multirow{4}{*}{$\begin{array}{c}\text { Hammerstones } \\
\text { with active } \\
\text { edge }\end{array}$} & Length & \multirow{4}{*}{3} & 123 & 66 & 88,7 & 30,2 & \multirow{4}{*}{20} & 140 & 68 & 88,1 & 15,7 \\
\hline & Width & & 93 & 62 & 73,7 & 16,9 & & 95 & 47 & 72,2 & 13,4 \\
\hline & Thickness & & 64 & 52 & 58,0 & 6,0 & & 88 & 27 & 59,5 & 14,6 \\
\hline & Weight & & 876,7 & 337,9 & 536,0 & 296,4 & & 1481,2 & 237,4 & 558,6 & 314,3 \\
\hline \multirow{4}{*}{$\begin{array}{c}\text { Hammerstones } \\
\text { with fracture } \\
\text { angles }\end{array}$} & Length & \multirow{4}{*}{7} & 129 & 67 & 98,9 & 21,4 & \multirow{4}{*}{19} & 111 & 41 & 78,3 & 21,0 \\
\hline & Width & & 108 & 52 & 84,3 & 20,4 & & 91 & 33 & 65,5 & 18,1 \\
\hline & Thickness & & 97 & 46 & 66,7 & 17,7 & & 77 & 24 & 55,8 & 15,6 \\
\hline & Weight & & 1704,2 & 321,7 & 879,4 & 536,1 & & 985,1 & 41,1 & 466,9 & 293,5 \\
\hline \multirow{4}{*}{ Pitted stones } & Length & \multirow{4}{*}{2} & 134 & 93 & 113,5 & 29,0 & \multirow{4}{*}{19} & 112 & 63 & 86,3 & 12,8 \\
\hline & Width & & 95 & 90 & 92,5 & 3,5 & & 98 & 45 & 68,8 & 14,1 \\
\hline & Thickness & & 84 & 65 & 74,5 & 13,4 & & 90 & 33 & 51,4 & 16,0 \\
\hline & Weight & & 1646,9 & 656,5 & 1151,7 & 700,3 & & 1803,6 & 175,3 & 505,5 & 450,2 \\
\hline \multirow{4}{*}{ PHFM } & Length & \multirow{4}{*}{0} & & & & & \multirow{4}{*}{2} & 74 & 60 & 67,0 & 9,9 \\
\hline & Width & & & & & & & 58 & 49 & 53,5 & 6,4 \\
\hline & Thickness & & & & & & & 38 & 35 & 36,5 & 2,1 \\
\hline & Weight & & & & & & & 212,9 & 139,0 & 176,0 & 52,3 \\
\hline \multirow{4}{*}{$\begin{array}{c}\text { Knapping } \\
\text { hammerstones }\end{array}$} & Length & \multirow{4}{*}{30} & 135 & 52 & 96,0 & 20,8 & \multirow{4}{*}{119} & 141 & 31 & 75,4 & 16,0 \\
\hline & Width & & 122 & 34 & 81,8 & 20,8 & & 99 & 30 & 60,7 & 12,9 \\
\hline & Thickness & & 98 & 13 & 60,9 & 17,2 & & 79 & 0 & 47,3 & 11,8 \\
\hline & Weight & & 2239,1 & 22,0 & 703,9 & 468,1 & & 1450,9 & 38,0 & 328,9 & 202,0 \\
\hline \multirow{4}{*}{ Subspheroids } & Length & \multirow{4}{*}{0} & & & & & \multirow{4}{*}{12} & 95 & 39 & 62,8 & 15,4 \\
\hline & Width & & & & & & & 82 & 29 & 56,0 & 14,0 \\
\hline & Thickness & & & & & & & 75 & 24 & 51,4 & 13,8 \\
\hline & Weight & & & & & & & 783,5 & 38,1 & 285,1 & 206,2 \\
\hline \multirow{4}{*}{$\begin{array}{l}\text { Utilised } \\
\text { material }\end{array}$} & Length & & & & & & & 88 & 66 & 74,7 & 8,1 \\
\hline & Width & 0 & & & & & 7 & 63 & 53 & 58,6 & 3,5 \\
\hline & Thickness & 0 & & & & & 1 & 57 & 34 & 43,1 & 9,7 \\
\hline & Weight & & & & & & & 378,1 & 158,1 & 251,7 & 75,6 \\
\hline & Length & & & & & & & 127 & 76 & 96,2 & 14,9 \\
\hline & Width & 0 & & & & & 0 & 108 & 58 & 77,3 & 18,3 \\
\hline Anvils & Thickness & 0 & & & & & 9 & 80 & 40 & 54,8 & 11,7 \\
\hline & Weight & & & & & & & 918,5 & 311,8 & 588,4 & 231,0 \\
\hline
\end{tabular}


Table 4

\begin{tabular}{|c|c|c|c|c|c|}
\hline & & \multicolumn{2}{|c|}{ EF-HR } & \multicolumn{2}{|c|}{ HWK EE } \\
\hline & & $\mathbf{N}$ & $\%$ & $\mathbf{N}$ & $\%$ \\
\hline \multirow{5}{*}{$\begin{array}{l}\text { Fractured knapping } \\
\text { hammerstones }\end{array}$} & Basalt & 1 & 12.5 & 23 & 18.7 \\
\hline & Quartzite & 3 & 37.5 & 29 & 23.6 \\
\hline & Phonolite & 2 & 25.0 & 47 & 38.2 \\
\hline & Indet. lava & 0 & 0.0 & 1 & 0.8 \\
\hline & Trachyte & 2 & 25.0 & 23 & 18.7 \\
\hline \multirow{5}{*}{$\begin{array}{l}\text { Hammerstones with } \\
\text { active edge }\end{array}$} & Basalt & 0 & 0.0 & 1 & 5.0 \\
\hline & Quartzite & 1 & 33.3 & 10 & 50.0 \\
\hline & Phonolite & 2 & 66.7 & 2 & 10.0 \\
\hline & Pumice & 0 & 0.0 & 1 & 5.0 \\
\hline & Trachyte & 0 & 0.0 & 6 & 30.0 \\
\hline \multirow{4}{*}{$\begin{array}{l}\text { Hammerstones with } \\
\text { fracture angles }\end{array}$} & Basalt & 4 & 57.1 & 8 & 42.1 \\
\hline & Quartzite & 1 & 14.3 & 6 & 31.6 \\
\hline & Phonolite & 1 & 14.3 & 2 & 10.5 \\
\hline & Trachyte & 1 & 14.3 & 3 & 15.8 \\
\hline \multirow{4}{*}{ Pitted stones } & Basalt & 2 & 100.0 & 8 & 42.1 \\
\hline & Phonolite & 0 & 0.0 & 7 & 36.8 \\
\hline & Pumice & 0 & 0.0 & 1 & 5.3 \\
\hline & Trachyte & 0 & 0.0 & 3 & 15.8 \\
\hline \multirow{2}{*}{ PHFM } & Phonolite & 0 & 0.0 & 1 & 50.0 \\
\hline & Trachyte & 0 & 0.0 & 1 & 50.0 \\
\hline \multirow{5}{*}{$\begin{array}{c}\text { Knapping } \\
\text { hammerstones }\end{array}$} & Basalt & 12 & 40.0 & 39 & 32.8 \\
\hline & Quartzite & 2 & 6.7 & 27 & 22.7 \\
\hline & Phonolite & 6 & 20.0 & 16 & 13.4 \\
\hline & Gneiss & 1 & 3.3 & 0 & 0.0 \\
\hline & Trachyte & 9 & 30.0 & 37 & 31.1 \\
\hline Subspheroids & Quartzite & 0 & 0.0 & 12 & 100.0 \\
\hline Utilised material & Quartzite & 0 & 0.0 & 7 & 100.0 \\
\hline Anvils & Quartzite & 0 & 0.0 & 9 & 100.0 \\
\hline
\end{tabular}


Table 5

\begin{tabular}{|c|c|c|c|c|c|}
\hline & & \multicolumn{2}{|c|}{ EF-HR } & \multicolumn{2}{|c|}{ HWK EE } \\
\hline & & $\mathbf{N}$ & $\%$ & $\mathbf{N}$ & $\%$ \\
\hline $\begin{array}{l}\text { Fractured knapping } \\
\text { hammerstones }\end{array}$ & Indet. & 8 & 100.0 & 123 & 100.0 \\
\hline \multirow{3}{*}{$\begin{array}{l}\text { Hammerstones with } \\
\text { active edge }\end{array}$} & Block & 0 & 0.0 & 6 & 30.0 \\
\hline & Cobble & 3 & 100.0 & 5 & 25.0 \\
\hline & Indet. & 0 & 0.0 & 9 & 45.0 \\
\hline \multirow{2}{*}{$\begin{array}{l}\text { Hammerstones with } \\
\text { fracture angles }\end{array}$} & Cobble & 7 & 100.0 & 13 & 68.4 \\
\hline & Indet. & 0 & 0.0 & 6 & 31.6 \\
\hline \multirow{2}{*}{ Pitted stones } & Cobble & 2 & 100.0 & 15 & 78.9 \\
\hline & Indet. & 0 & 0.0 & 4 & 21.1 \\
\hline \multirow{2}{*}{ PHFM } & Cobble & 0 & 0.0 & 1 & 50.0 \\
\hline & Indet. & 0 & 0.0 & 1 & 50.0 \\
\hline \multirow{4}{*}{$\begin{array}{l}\text { Knapping } \\
\text { hammerstones }\end{array}$} & Block & 0 & 0.0 & 5 & 4.2 \\
\hline & Cobble & 23 & 76.7 & 90 & 75.6 \\
\hline & Fragment & 1 & 3.3 & 0 & 0.0 \\
\hline & Indet. & 6 & 20.0 & 24 & 20.2 \\
\hline \multirow{3}{*}{ Subspheroids } & Block & 0 & 0.0 & 1 & 8.3 \\
\hline & Cobble & 0 & 0.0 & 1 & 8.3 \\
\hline & Indet. & 0 & 0.0 & 10 & 83.3 \\
\hline \multirow{3}{*}{ Utilised material } & Block & 0 & 0.0 & 4 & 57.1 \\
\hline & Cobble & 0 & 0.0 & 1 & 14.3 \\
\hline & Indet. & 0 & 0.0 & 2 & 28.6 \\
\hline \multirow{2}{*}{ Anvils } & Block & 0 & 0.0 & 5 & 55.6 \\
\hline & Indet. & 0 & 0.0 & 4 & 44.4 \\
\hline
\end{tabular}




\begin{tabular}{ccccccccc}
\hline ID & Category & Blank & $\begin{array}{c}\text { Area } \\
\left(\mathbf{m m}^{2}\right)\end{array}$ & $\begin{array}{c}\text { Perimeter } \\
(\mathbf{m m})\end{array}$ & Circularity & $\begin{array}{c}\text { Aspect Ratio } \\
\text { (AR) }\end{array}$ & Roundness & Solidity \\
\hline L6-1692 & HFA & Indet & 1712.49 & 165.527 & 0.785 & 1.041 & 0.96 & 0.973 \\
L2-712 & HFA & Indet & 1492.53 & 159.276 & 0.739 & 1.204 & 0.831 & 0.975 \\
T27L31-55 & HFA & Indet & 2963.83 & 225.664 & 0.731 & 1.189 & 0.841 & 0.968 \\
L1E-168 & HFA & Indet & 2023.67 & 172.481 & 0.855 & 1.018 & 0.983 & 0.985 \\
LCHA-518 & HFA & Cobble & 1553.84 & 151.318 & 0.853 & 1.049 & 0.953 & 0.986 \\
L6-837 & Subspheroid & Block & 5780.81 & 302.705 & 0.793 & 1.169 & 0.855 & 0.972 \\
LCHA-1050 & Subspheroid & Indet & 3659.66 & 230.895 & 0.863 & 1.069 & 0.935 & 0.988 \\
L1E-152 & Subspheroid & Indet & 3943.83 & 248.412 & 0.803 & 1.168 & 0.856 & 0.978 \\
L10-2495 & Subspheroid & Indet & 3128.27 & 220.42 & 0.809 & 1.092 & 0.916 & 0.973 \\
L6-951 & Subspheroid & Indet & 2754.34 & 205.24 & 0.822 & 1.153 & 0.867 & 0.984 \\
L1-2540 & Subspheroid & Indet & 2488.26 & 195.084 & 0.822 & 1.211 & 0.826 & 0.982 \\
LCHA-1081 & Subspheroid & Indet & 2038.66 & 177.781 & 0.811 & 1.135 & 0.881 & 0.972 \\
L6-1044 & Subspheroid & Cobble & 2019.42 & 172.878 & 0.849 & 1.037 & 0.965 & 0.983 \\
L10-1421 & Subspheroid & Indet & 2196.56 & 182.052 & 0.833 & 1.093 & 0.915 & 0.978 \\
T29L50-96 & Subspheroid & Indet & 1215.77 & 136.613 & 0.819 & 1.078 & 0.928 & 0.975 \\
L2-530 & Subspheroid & Indet & 707.49 & 103.612 & 0.828 & 1.307 & 0.765 & 0.979 \\
T27L30-7 & Subspheroid & Indet & 1762.5 & 163.511 & 0.828 & 1.083 & 0.923 & 0.984 \\
\hline
\end{tabular}


Table 7

\begin{tabular}{|c|c|c|c|c|c|}
\hline \multirow[b]{2}{*}{ Total } & & \multicolumn{2}{|l|}{ EF-HR } & \multicolumn{2}{|l|}{ HWK EE } \\
\hline & & N Objects with battering & $\%$ & N Objects with battering & $\%$ \\
\hline Cores & Bipolar Cores & 9 & 6,47 & 74 & 8,00 \\
\hline EF-HR $(n=139)$ & Cores with écaillés & 7 & 5,04 & 58 & 6,27 \\
\hline HWK EE (n= 925) & Cores with percussive marks & 28 & 20,14 & 217 & 23,46 \\
\hline $\begin{array}{l}\text { Flakes } \\
\text { EF-HR }(n=524)\end{array}$ & Flakes with écaillés & 6 & 1,15 & 81 & 5,92 \\
\hline HWK EE $(n=1368)$ & Flakes with percussive marks & 2 & 0,38 & 76 & 5,56 \\
\hline $\begin{array}{l}\text { Flake fragments } \\
\text { EF-HR }(n=884)\end{array}$ & Flake fragments with écaillés & 2 & 0,23 & 46 & 1,49 \\
\hline HWK EE $(n=3081)$ & Flake fragments with percussive marks & 13 & 1,47 & 117 & 3,80 \\
\hline $\begin{array}{l}\text { Angular fragments } \\
\text { EF-HR }(n=121)\end{array}$ & Angular fragments with écaillés & 0 & 0,00 & 4 & 0,41 \\
\hline HWK EE $(n=964)$ & Angular fragments with percussive marks & 1 & 0,83 & 137 & 14,21 \\
\hline
\end{tabular}


Table 8

\begin{tabular}{|c|c|c|c|c|c|c|c|c|c|}
\hline & \multicolumn{5}{|c|}{ HWK EE } & \multicolumn{3}{|c|}{ EF-HR } & \multirow[b]{2}{*}{$\begin{array}{c}\text { Total objects } \\
\text { analysed }\end{array}$} \\
\hline & Qtz & $\mathrm{Ba}$ & $\mathrm{Ph}$ & $\mathrm{Pu}$ & $\mathrm{T} / \mathrm{Tr}$ & Qtz & Gn & $\mathrm{T} / \mathrm{Tr}$ & \\
\hline Fractured hammestone & 0 & 0 & 1 & 0 & 0 & 0 & 0 & 0 & 1 \\
\hline $\begin{array}{l}\text { Knapping } \\
\text { hammerstones }\end{array}$ & 6 & 1 & 0 & 0 & 0 & 0 & 1 & 3 & 11 \\
\hline HAE & 5 & 0 & 1 & 0 & 1 & 1 & 0 & 0 & 8 \\
\hline HFA & 4 & 0 & 0 & 0 & 1 & 1 & 0 & 0 & 6 \\
\hline Core-hammerstones & 2 & 0 & 0 & 0 & 0 & 1 & 0 & 0 & 3 \\
\hline Subspheroids & 11 & 0 & 0 & 0 & 0 & 0 & 0 & 0 & 11 \\
\hline Pitted Stones & 0 & 1 & 0 & 1 & 0 & 0 & 0 & 0 & 2 \\
\hline Anvils & 7 & 0 & 0 & 0 & 0 & 0 & 0 & 0 & 7 \\
\hline Total & 35 & 2 & 2 & 1 & 2 & 3 & 1 & 3 & 49 \\
\hline
\end{tabular}


Table 9

\begin{tabular}{|c|c|c|c|c|c|c|c|c|c|c|c|c|c|c|c|c|c|c|c|c|c|c|c|c|c|}
\hline & \multirow[b]{3}{*}{$\begin{array}{c}\text { Total objects } \\
\text { analysed }\end{array}$} & \multicolumn{4}{|c|}{ Linear Traces } & \multicolumn{4}{|c|}{ Polish/abrasion } & \multicolumn{4}{|c|}{ Pits } & \multicolumn{4}{|c|}{ Micro-fractures } & \multicolumn{4}{|c|}{ Impact points } & \multicolumn{4}{|c|}{ Crushing } \\
\hline & & \multicolumn{2}{|c|}{ Absent } & \multicolumn{2}{|c|}{ Present } & \multicolumn{2}{|c|}{ Absent } & \multicolumn{2}{|c|}{ Present } & \multicolumn{2}{|c|}{ Absent } & \multicolumn{2}{|c|}{ Present } & \multicolumn{2}{|c|}{ Absent } & \multicolumn{2}{|c|}{ Present } & \multicolumn{2}{|c|}{ Absent } & \multicolumn{2}{|c|}{ Present } & \multicolumn{2}{|c|}{ Absent } & \multicolumn{2}{|c|}{ Present } \\
\hline & & N & $\begin{array}{c}\text { Column } \\
\%\end{array}$ & $\mathrm{~N}$ & $\begin{array}{c}\text { Column } \\
\%\end{array}$ & $\mathrm{~N}$ & $\begin{array}{c}\text { Column } \\
\%\end{array}$ & $\mathrm{~N}$ & $\begin{array}{c}\text { Column } \\
\%\end{array}$ & $\mathrm{~N}$ & $\begin{array}{c}\text { Column } \\
\%\end{array}$ & $\mathrm{~N}$ & $\begin{array}{c}\text { Column } \\
\%\end{array}$ & $\mathrm{~N}$ & $\begin{array}{c}\text { Column } \\
\%\end{array}$ & $\mathrm{~N}$ & $\begin{array}{c}\text { Column } \\
\%\end{array}$ & N & $\begin{array}{c}\text { Column } \\
\%\end{array}$ & $\mathrm{~N}$ & $\begin{array}{c}\text { Column } \\
\%\end{array}$ & $\mathrm{~N}$ & $\begin{array}{c}\text { Column } \\
\%\end{array}$ & $N$ & $\begin{array}{c}\text { Column } \\
\%\end{array}$ \\
\hline Fractured hammestone & 1 & 1 & 2.1 & 0 & 0.0 & 1 & 2.2 & 0 & 0.0 & 1 & 2.7 & 0 & 0.0 & 1 & 10.0 & 0 & 0.0 & 1 & 16.7 & 0 & 0.0 & 1 & 12.5 & 0 & 0.0 \\
\hline $\begin{array}{l}\text { Knapping } \\
\text { hammerstones }\end{array}$ & 11 & 11 & 22.9 & 0 & 0.0 & 8 & 17.8 & 3 & 75.0 & 7 & 18.9 & 4 & 33.3 & 2 & 20.0 & 9 & 23.1 & 3 & 50.0 & 8 & 18.6 & 4 & 50.0 & 7 & 17.1 \\
\hline HAE & 8 & 8 & 16.7 & 0 & 0.0 & 8 & 17.8 & 0 & 0.0 & 7 & 18.9 & 1 & 8.3 & 2 & 20.0 & 6 & 15.4 & 2 & 33.3 & 6 & 14.0 & 2 & 25.0 & 6 & 14.6 \\
\hline HFA & 6 & 6 & 12.5 & 0 & 0.0 & 6 & 13.3 & 0 & 0.0 & 4 & 10.8 & 2 & 16.7 & 0 & 0.0 & 6 & 15.4 & 0 & 0.0 & 6 & 14.0 & 1 & 12.5 & 5 & 12.2 \\
\hline Core-hammerstones & 3 & 3 & 6.3 & 0 & 0.0 & 3 & 6.7 & 0 & 0.0 & 2 & 5.4 & 1 & 8.3 & 0 & 0.0 & 3 & 7.7 & 0 & 0.0 & 3 & 7.0 & 0 & 0.0 & 3 & 7.3 \\
\hline Subspheroids & 11 & 11 & 22.9 & 0 & 0.0 & 11 & 24.4 & 0 & 0.0 & 8 & 21.6 & 3 & 25.0 & 3 & 30.0 & 8 & 20.5 & 0 & 0.0 & 11 & 25.6 & 0 & 0.0 & 11 & 26.8 \\
\hline Pitted Stones & 2 & 2 & 4.2 & 0 & 0.0 & 2 & 4.4 & 0 & 0.0 & 2 & 5.4 & 0 & 0.0 & 0 & 0.0 & 2 & 5.1 & 0 & 0.0 & 2 & 4.7 & 0 & 0.0 & 2 & 4.9 \\
\hline Anvils & 7 & 6 & 12.5 & 1 & 100.0 & 6 & 13.3 & 1 & 25.0 & 6 & 16.2 & 1 & 8.3 & 2 & 20.0 & 5 & 12.8 & 0 & 0.0 & 7 & 16.3 & 0 & 0.0 & 7 & 17.1 \\
\hline
\end{tabular}


Table 10

\begin{tabular}{|c|c|c|c|c|c|c|c|c|c|}
\hline & Culture & Stratigraphic position & $\begin{array}{l}\text { Hammerstones, } \\
\text { HAE and HFA }\end{array}$ & $\begin{array}{l}\text { Spheroids/ } \\
\text { subspheroids }\end{array}$ & $\begin{array}{l}\text { Anvils and } \\
\text { PHFM }\end{array}$ & Pitted stones & $\begin{array}{l}\text { Utilised material/ } \\
\text { modified battered nodules and blocks }\end{array}$ & Total & Reference \\
\hline HWK E (Levels 3, 4, 5) & Oldowan & Middle Bed II & 23 & 114 & 19 & 0 & 202 & 358 & Leakey, 1971 \\
\hline HWK EE (OGAP) & Oldowan & Middle Bed II & 281 & 12 & 11 & 19 & 7 & 330 & This work \\
\hline HWK EE (Leakey) & Oldowan & Middle Bed II & 70 & 7 & 1 & 3 & $8^{* *}$ & 89 & Pante and de la Torre, this volume \\
\hline FLK N Sandy Conglomerate & Oldowan & Middle Bed II & 35 & 47 & 2 & 0 & 0 & 84 & de la Torre and Mora, 2005 \\
\hline MNK Skull & Oldowan & Middle Bed II & 15 & 6 & 3 & 0 & 54 & 78 & Leakey, 1971 \\
\hline FC West & Acheulean & Middle Bed II & 115 & 0 & 8 & 0 & 0 & 123 & de la Torre and Mora, 2005 \\
\hline MNK Main & Acheulean & Middle Bed II & 64 & 159 & 24 & 0 & 199 & 446 & Leakey, 1971 \\
\hline EF-HR & Acheulean & Upper Bed II & 48 & 0 & 0 & 2 & 0 & 50 & This work \\
\hline SHK & Acheulean & Upper Bed II & * & 318 & 26 & 0 & 115 & 459 & Leakey, 1971 \\
\hline BK & Acheulean & Upper Bed II & 43 & 446 & 23 & 0 & 394 & 906 & Leakey, 1971 \\
\hline TK & Acheulean & Upper Bed II & 63 & 52 & 51 & 0 & 0 & 166 & de la Torre and Mora, 2005 \\
\hline
\end{tabular}



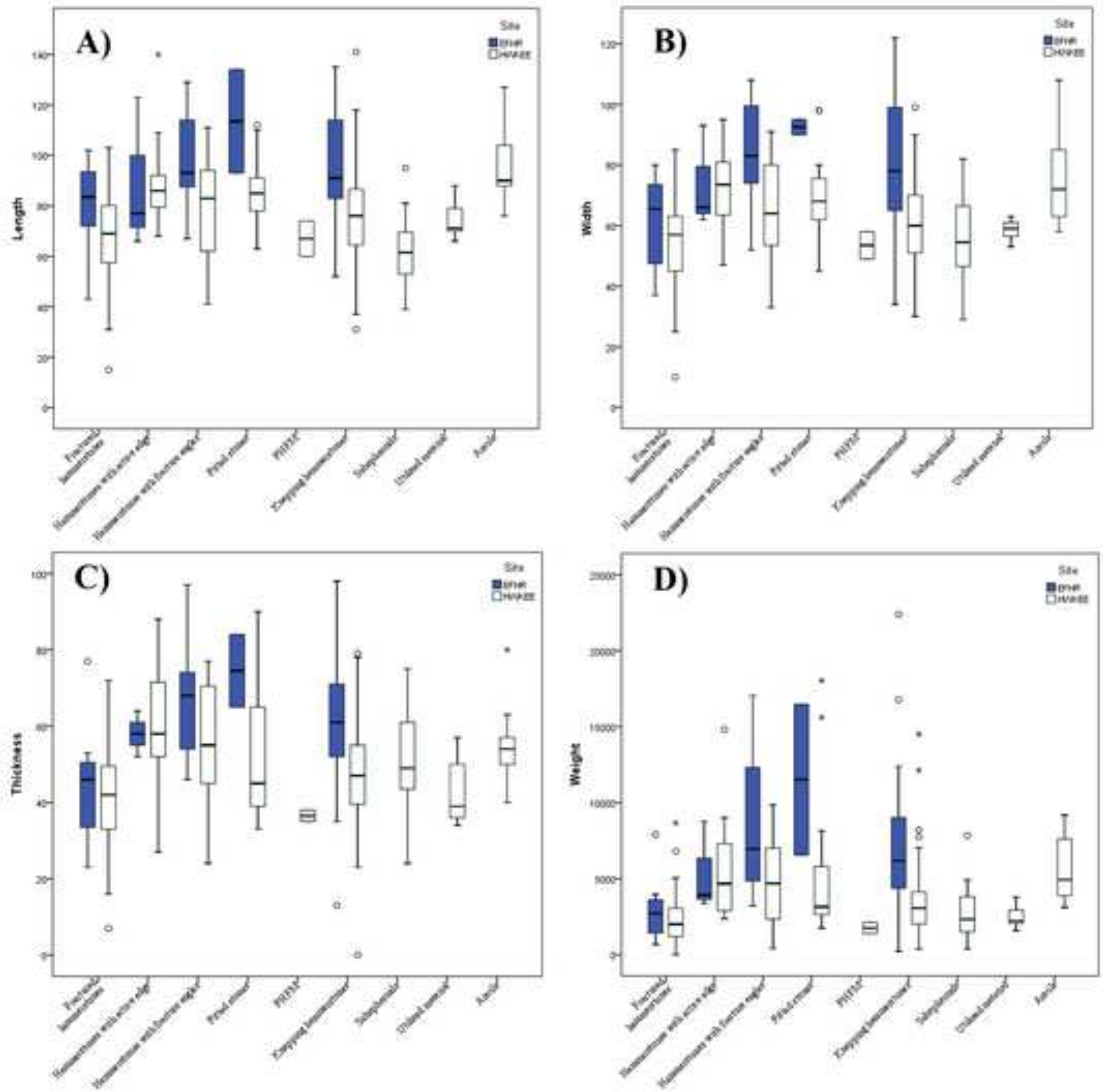


\section{Figure}

Click here to download high resolution image

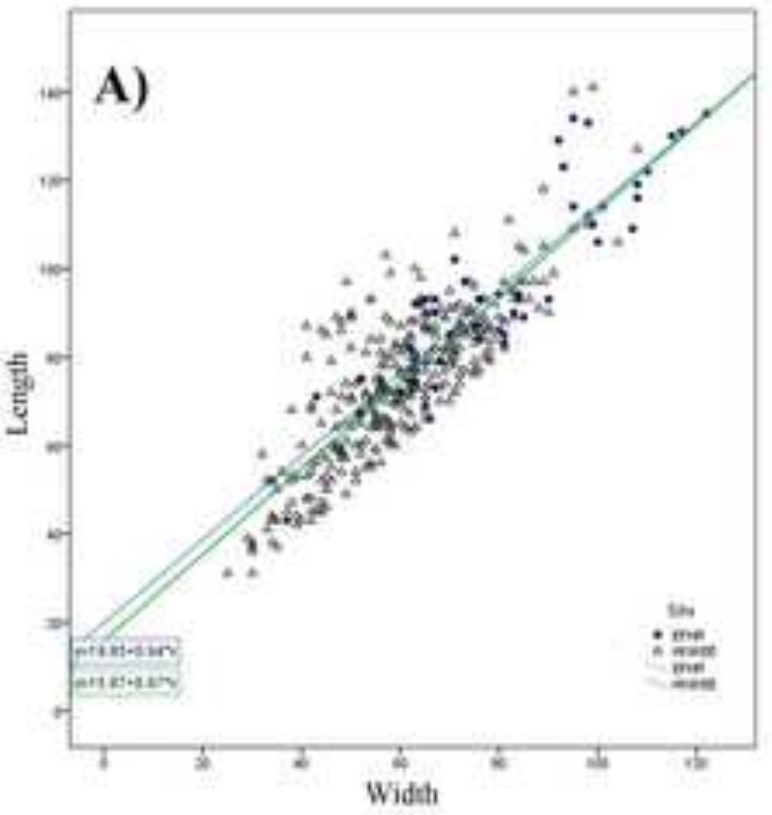

B)
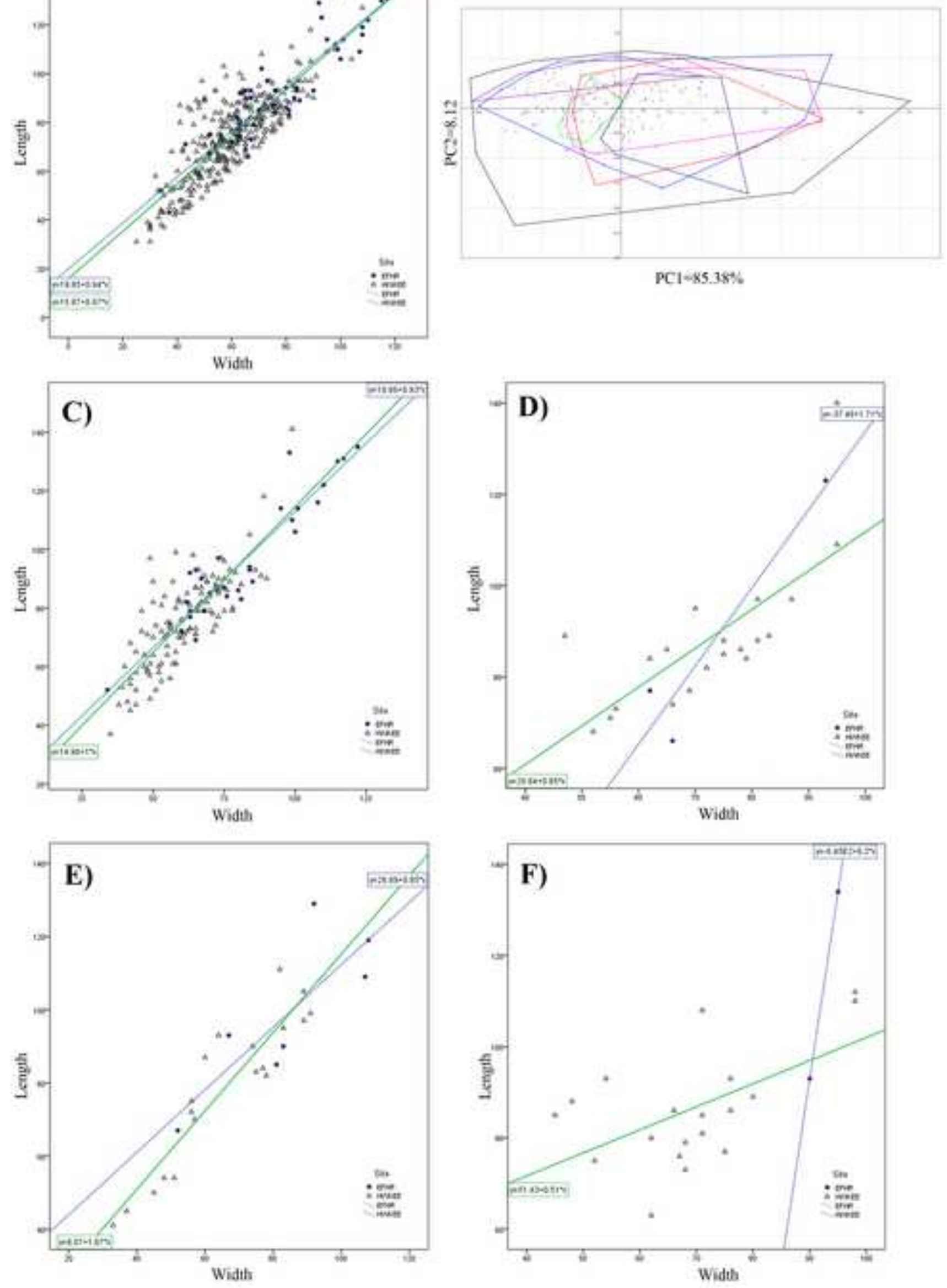


\section{Figure 3 \\ Click here to download high resolution image}

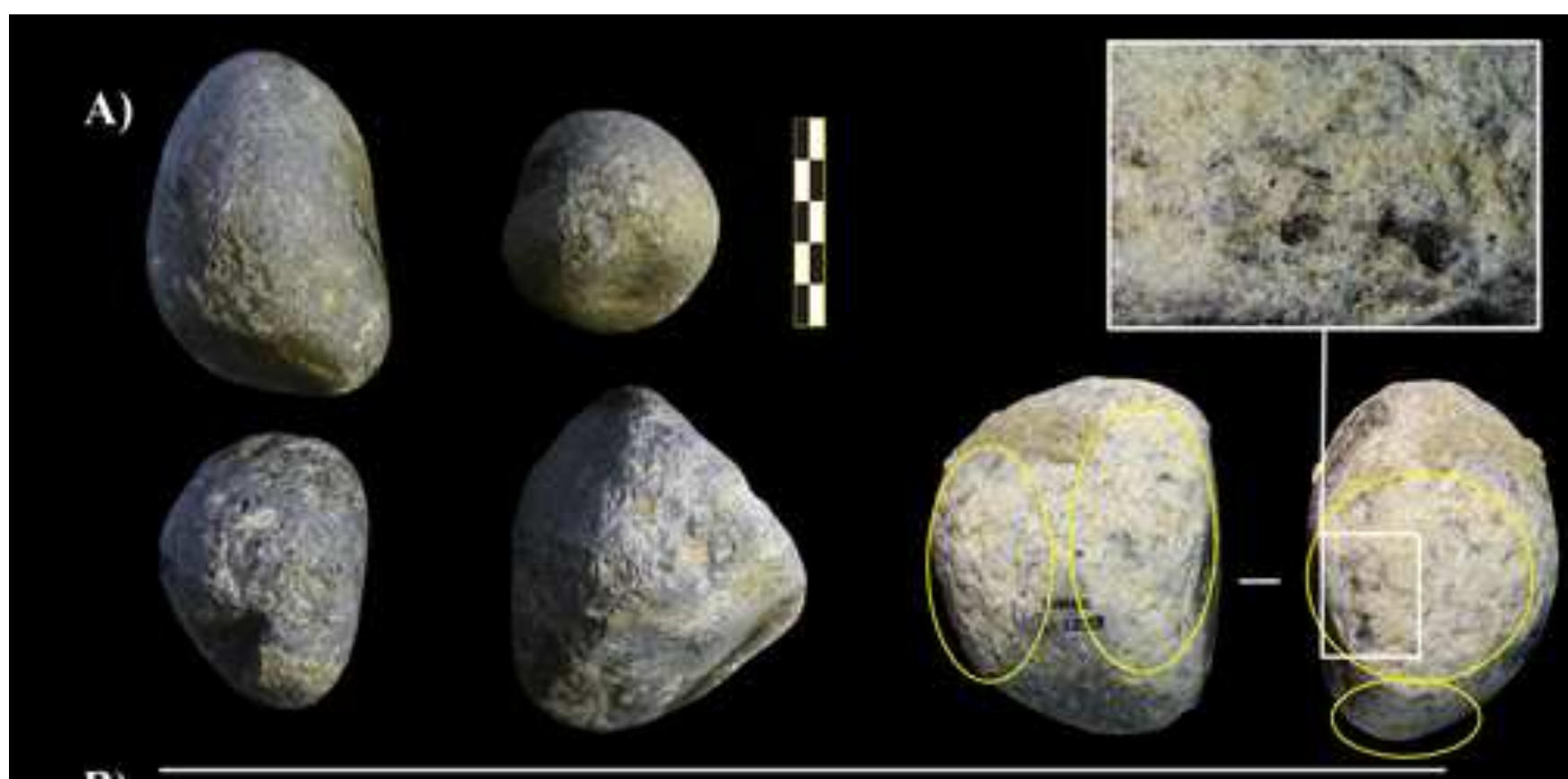

B)
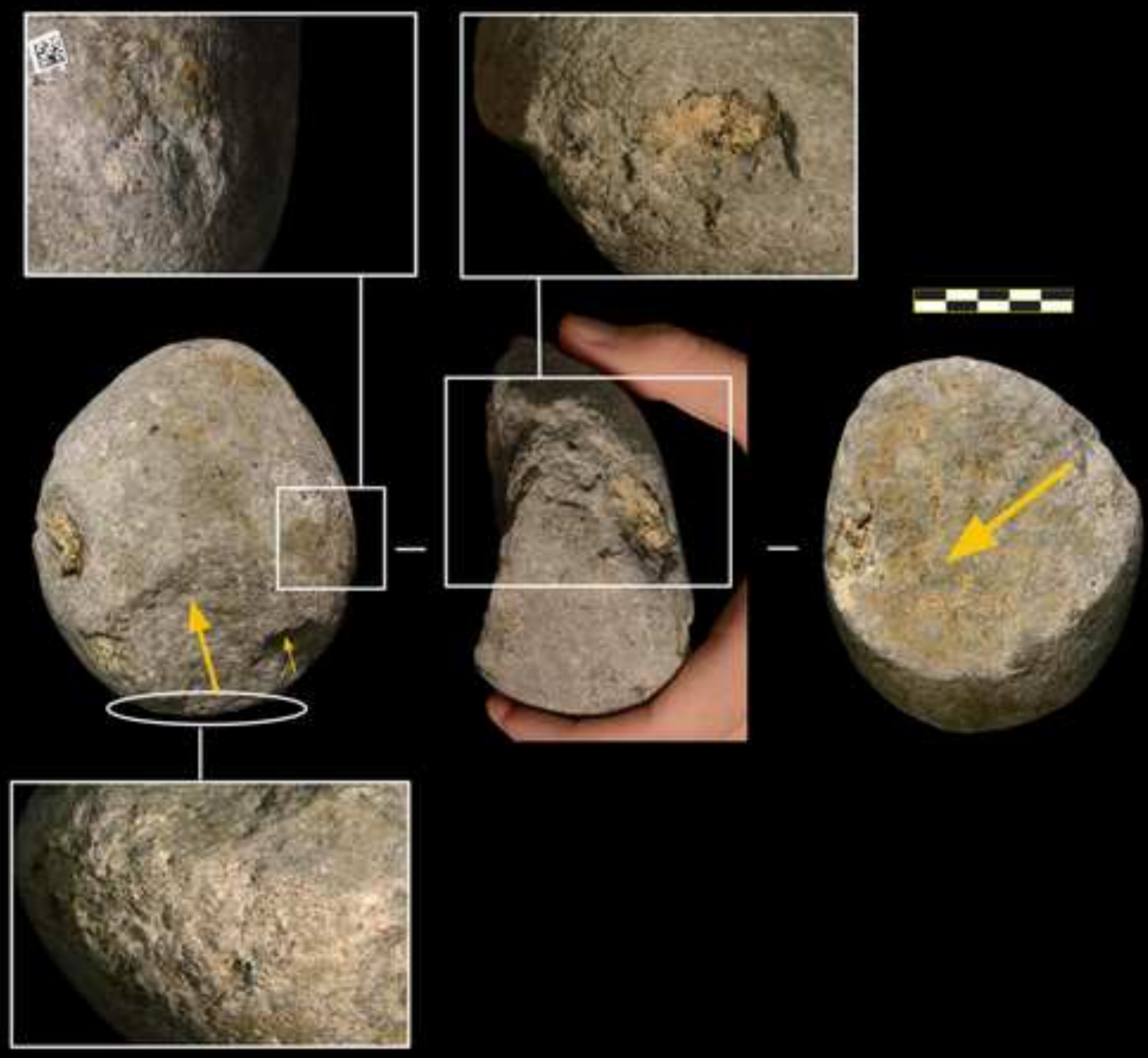


\section{Click here to download high resolution image}

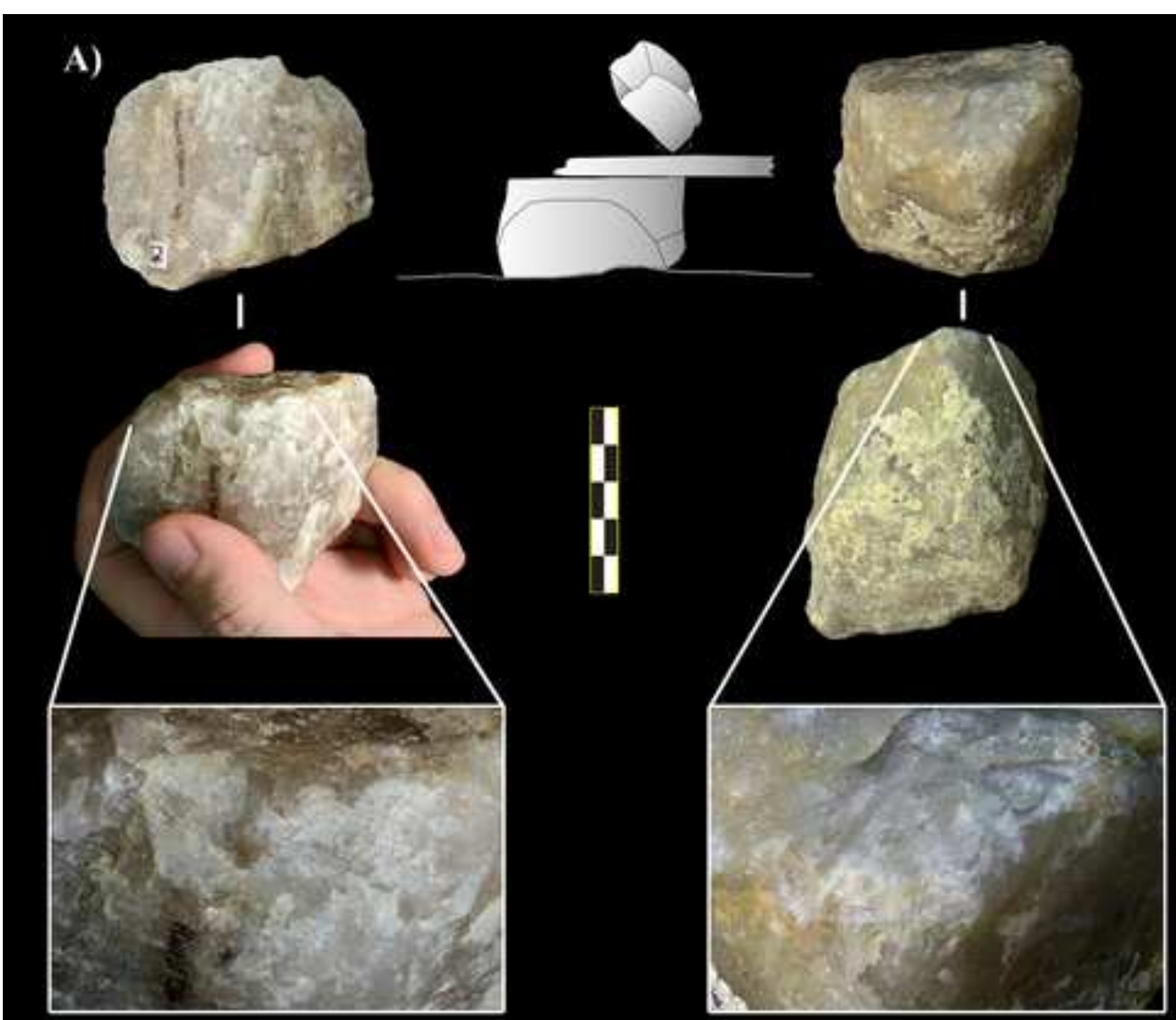

B)

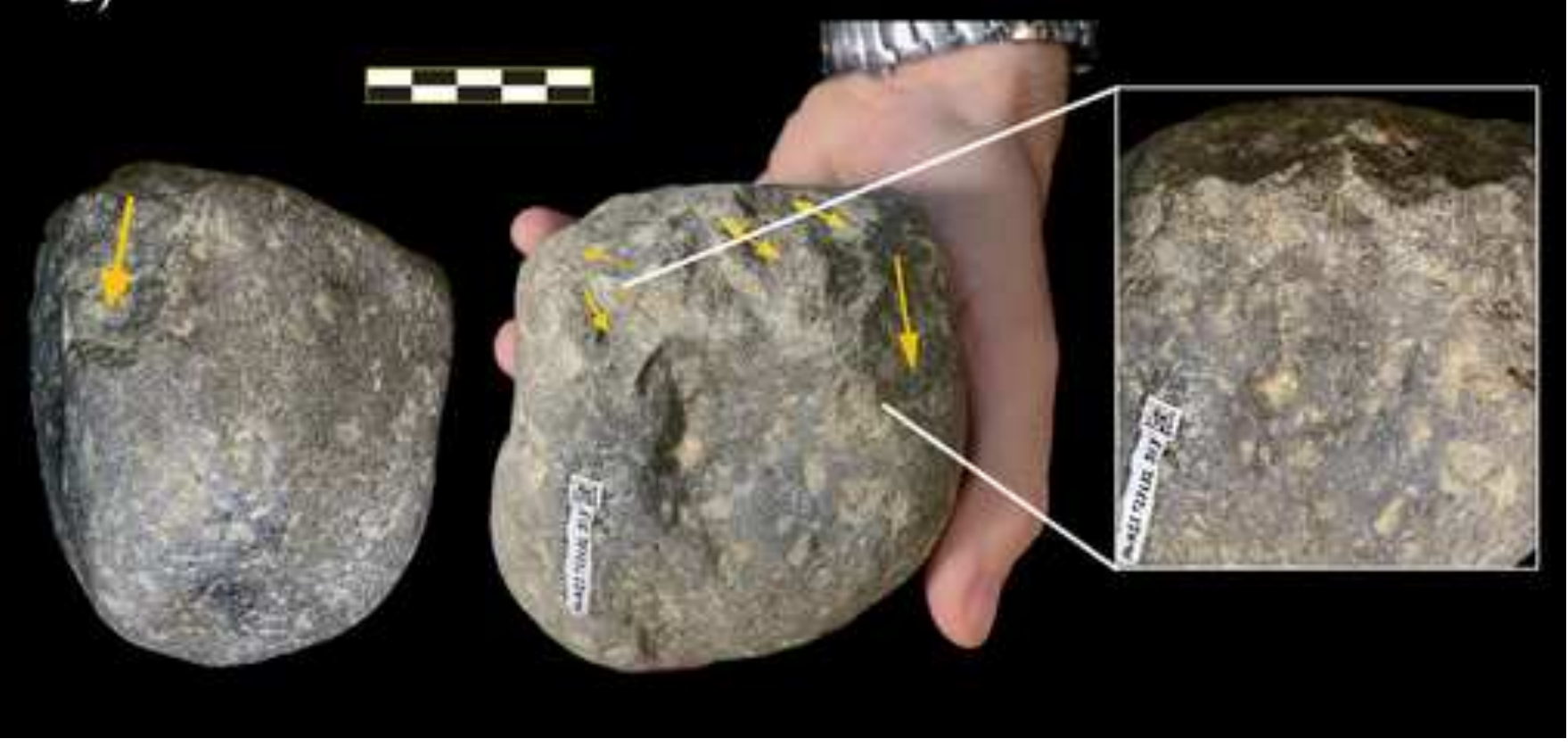




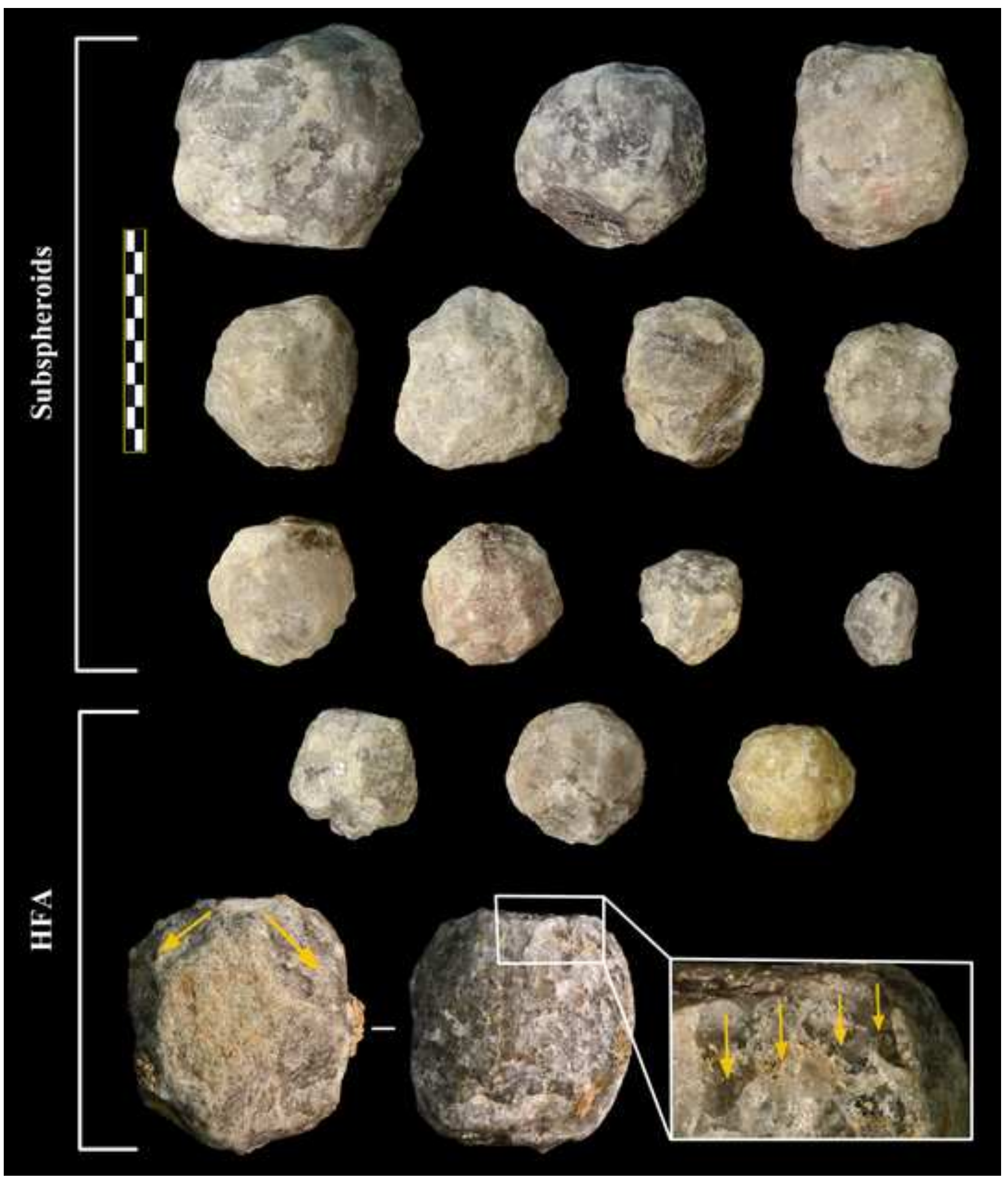




\section{Click here to download high resolution image}

A)
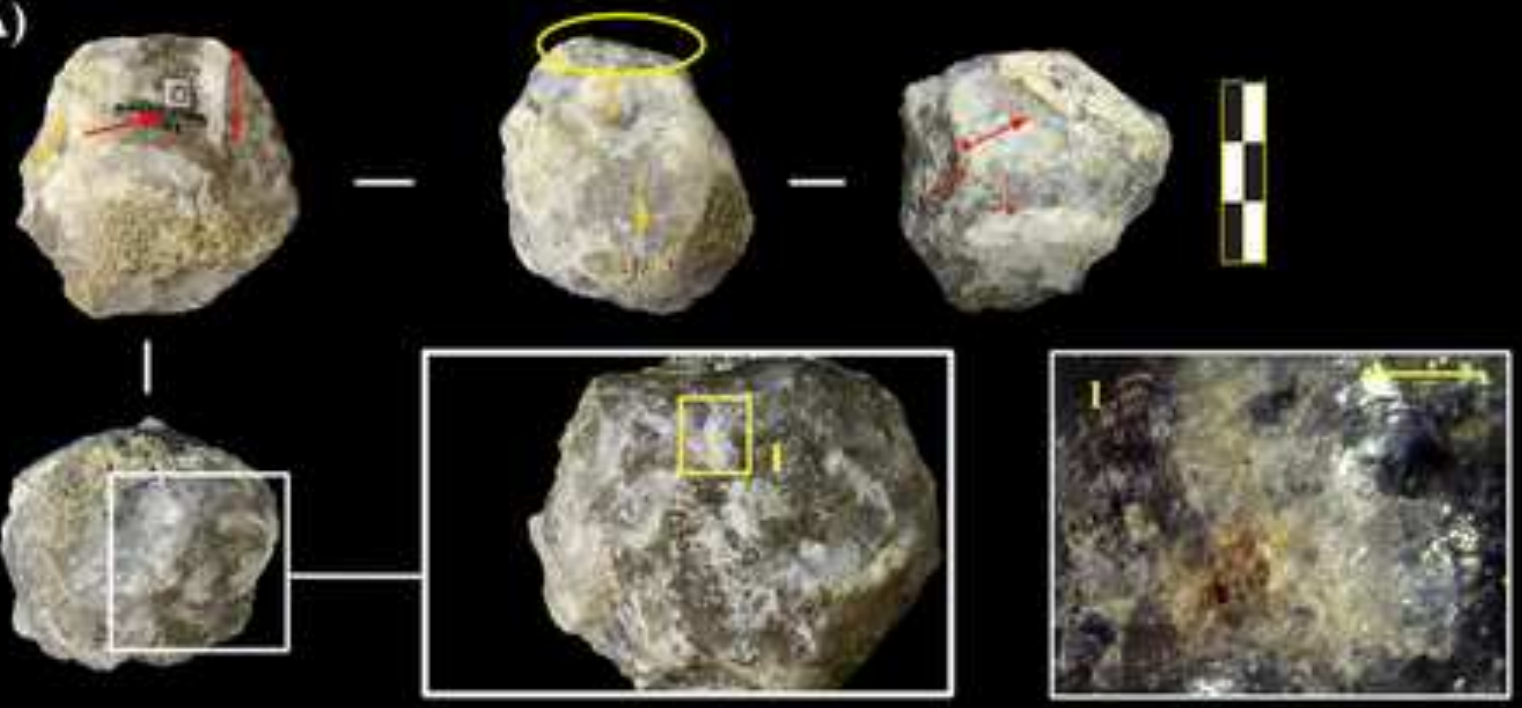

B)

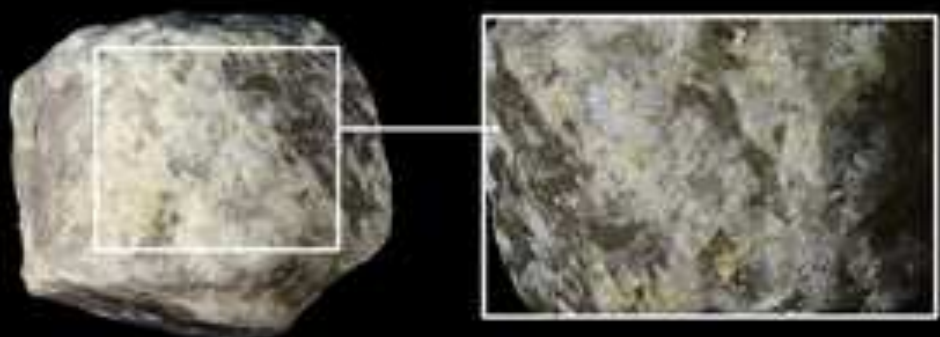

,
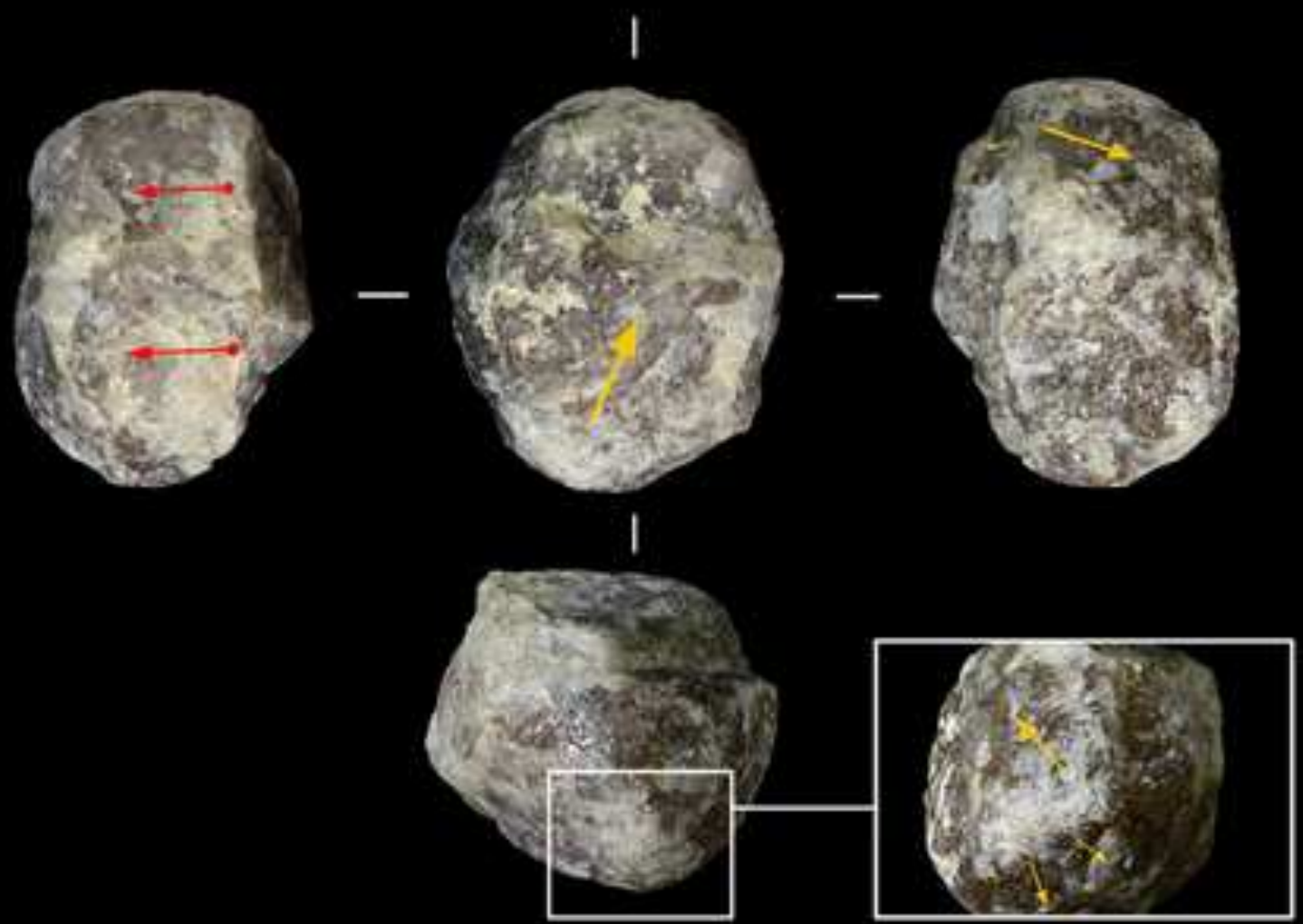


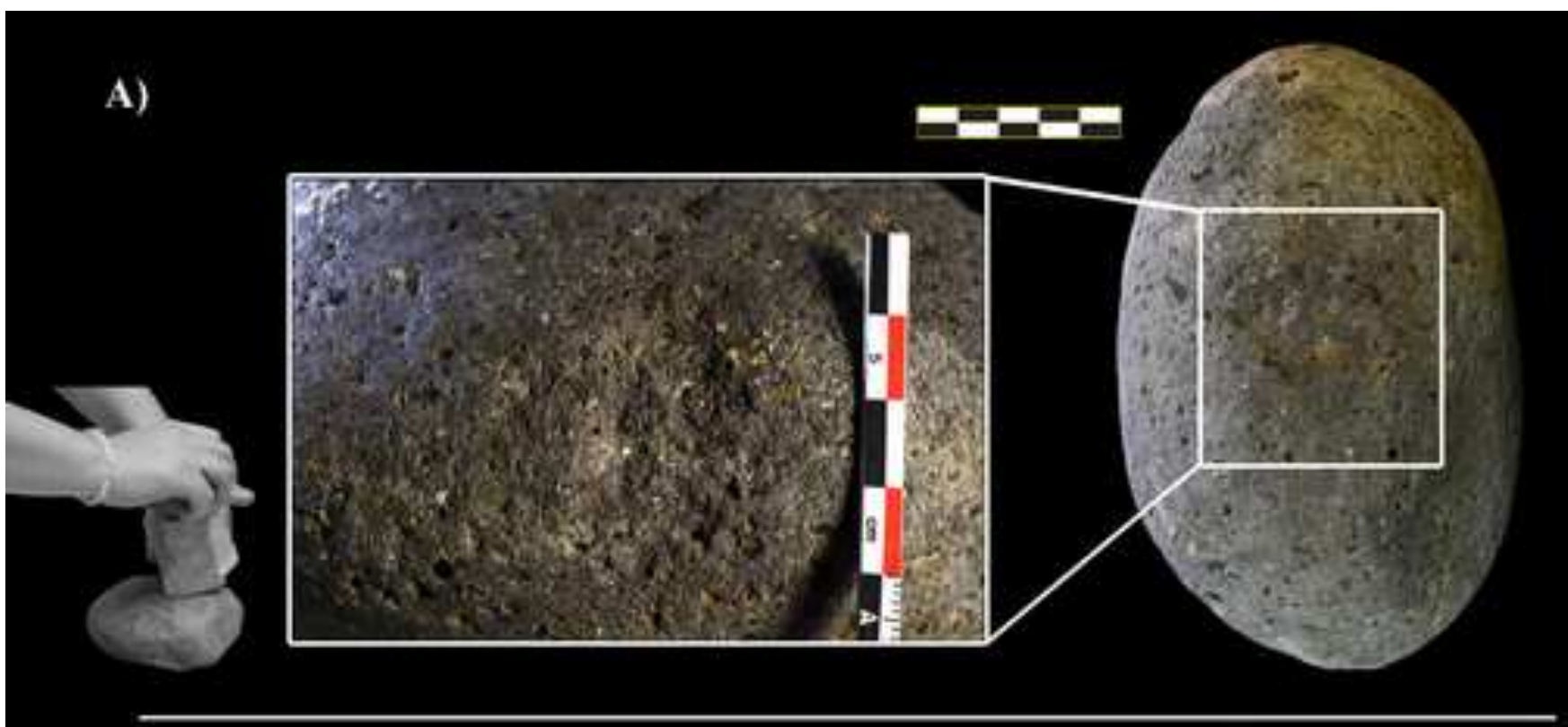

B)
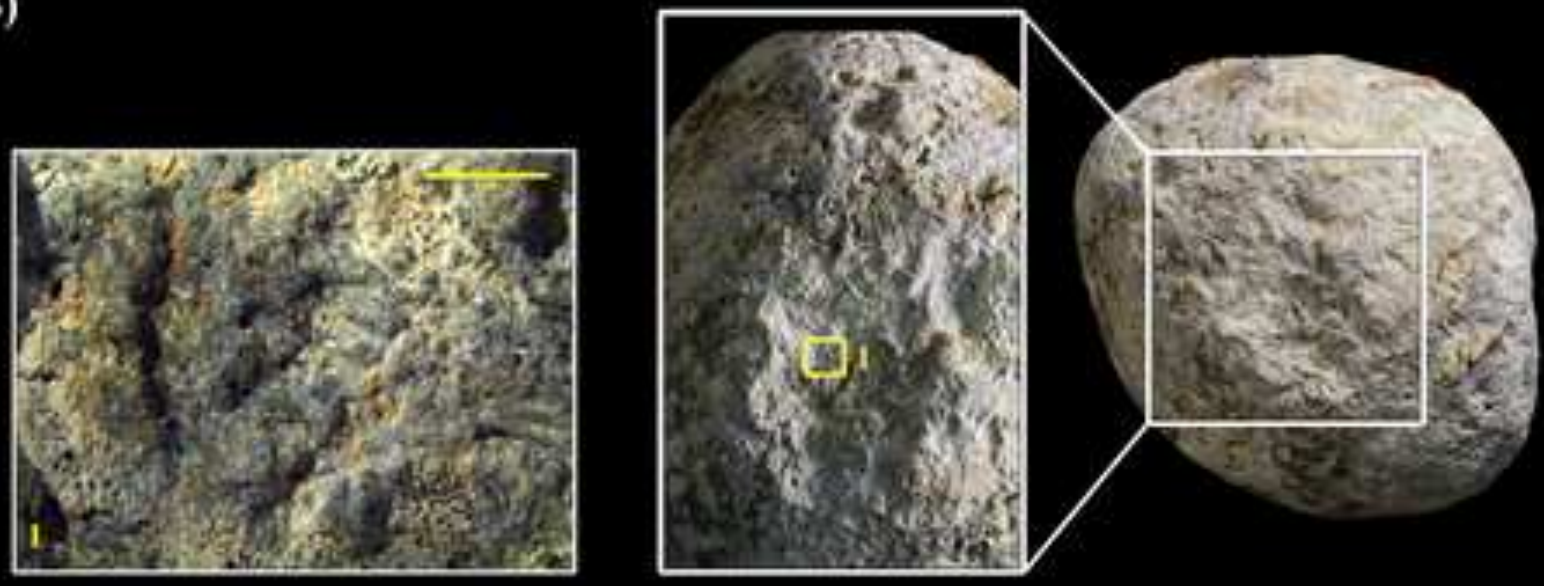

C)
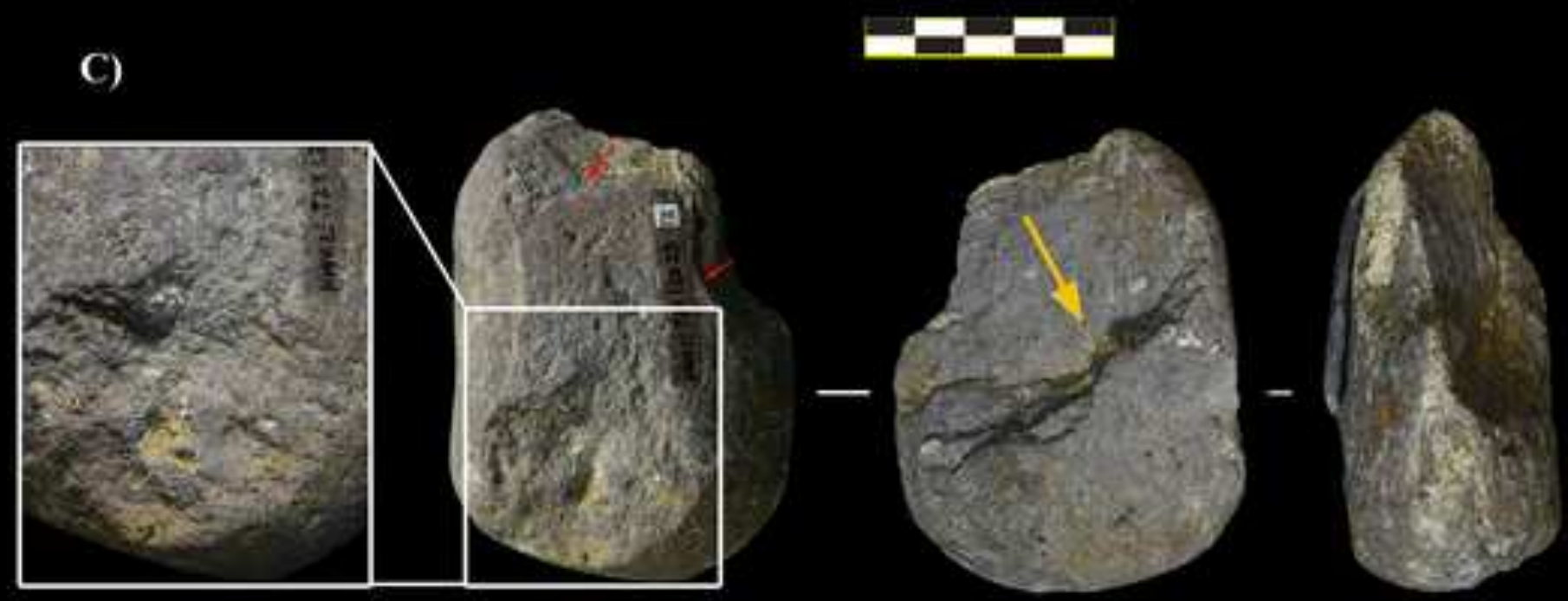
Figure 8

Click here to download high resolution image
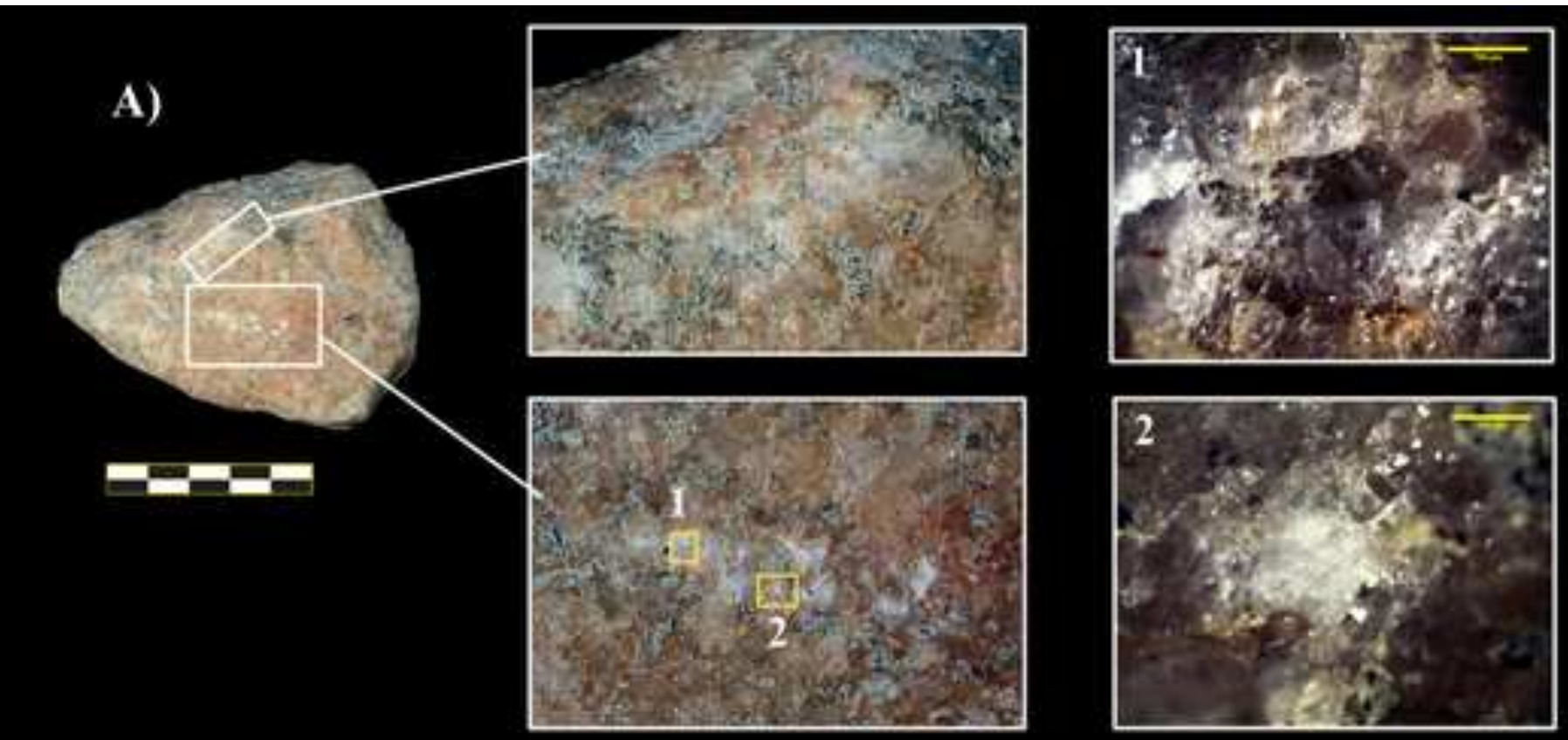

B)
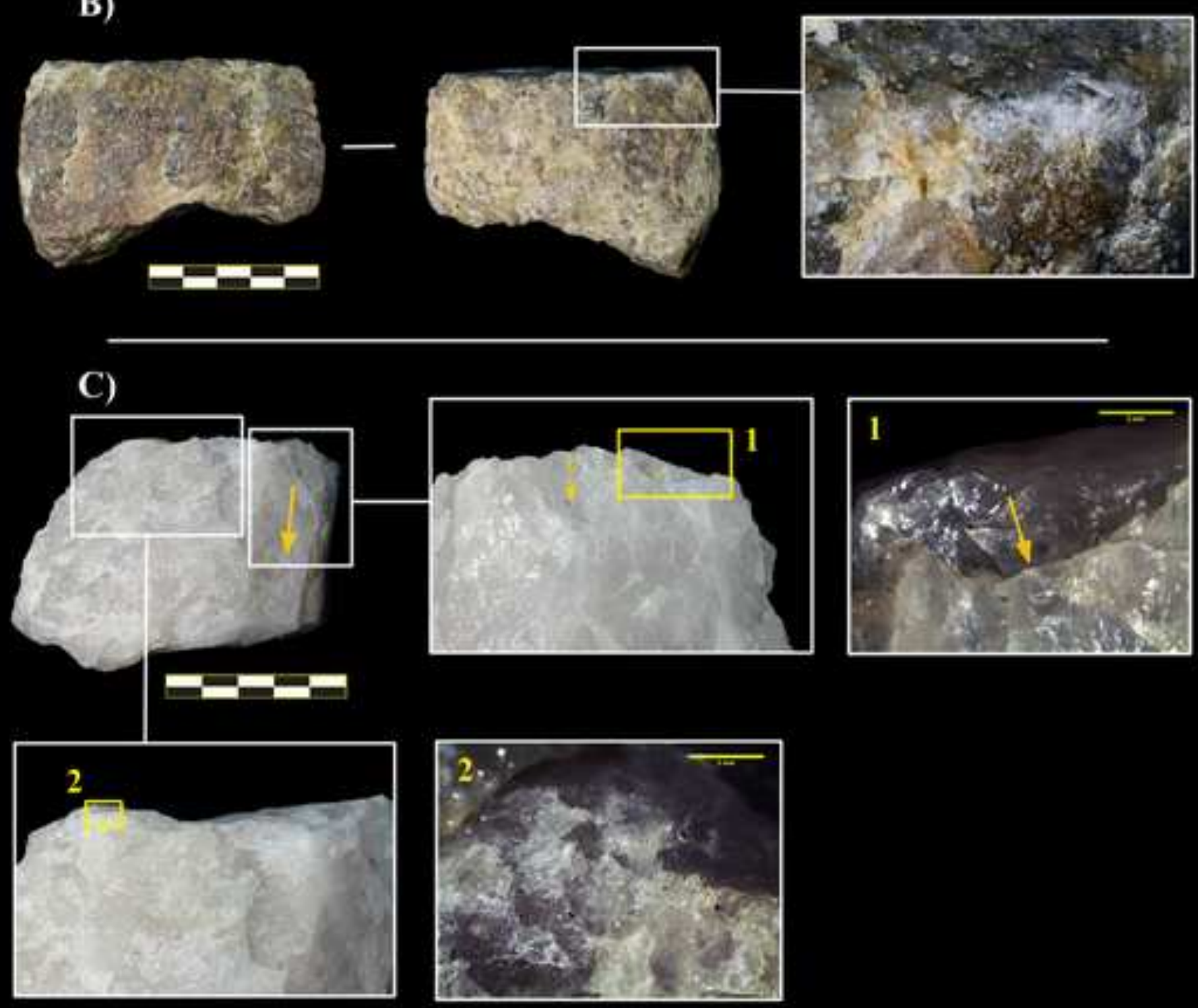
Click here to download high resolution image

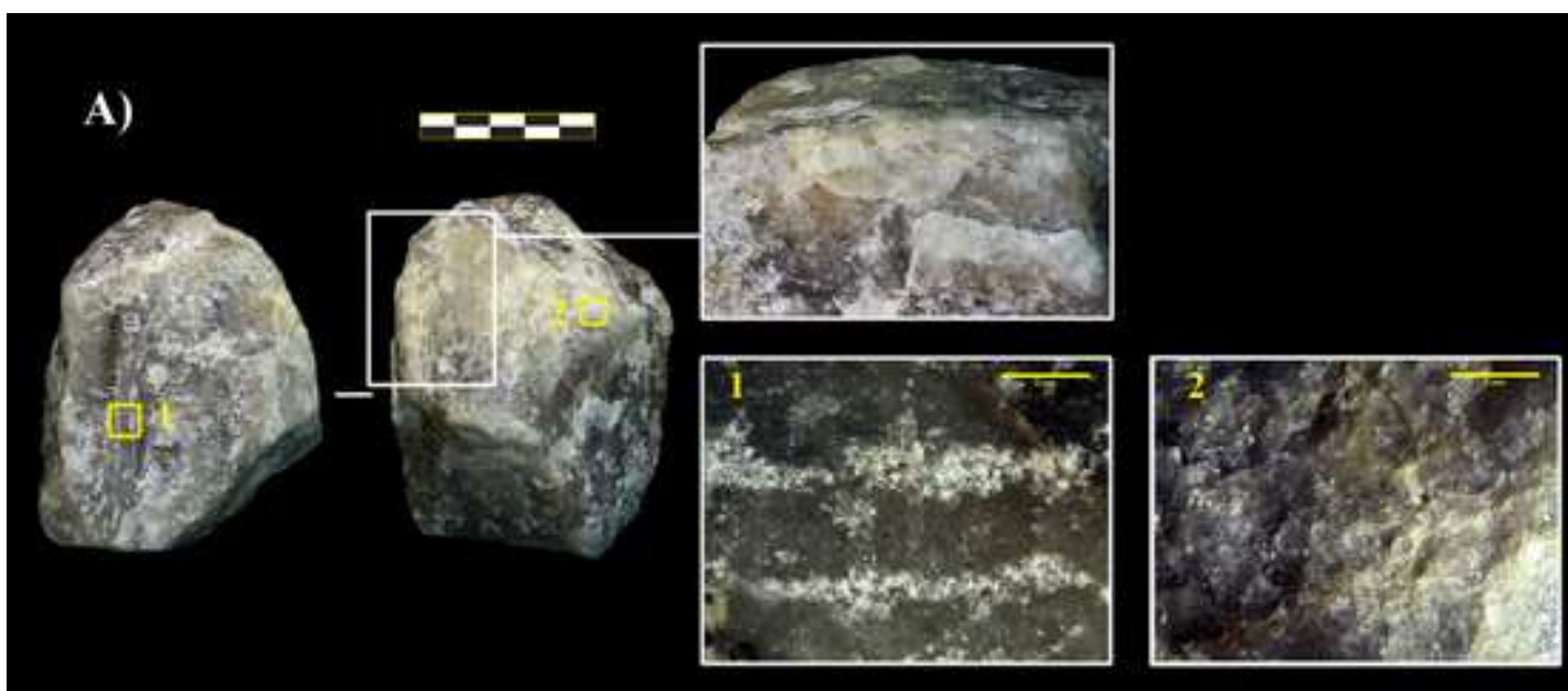

B)
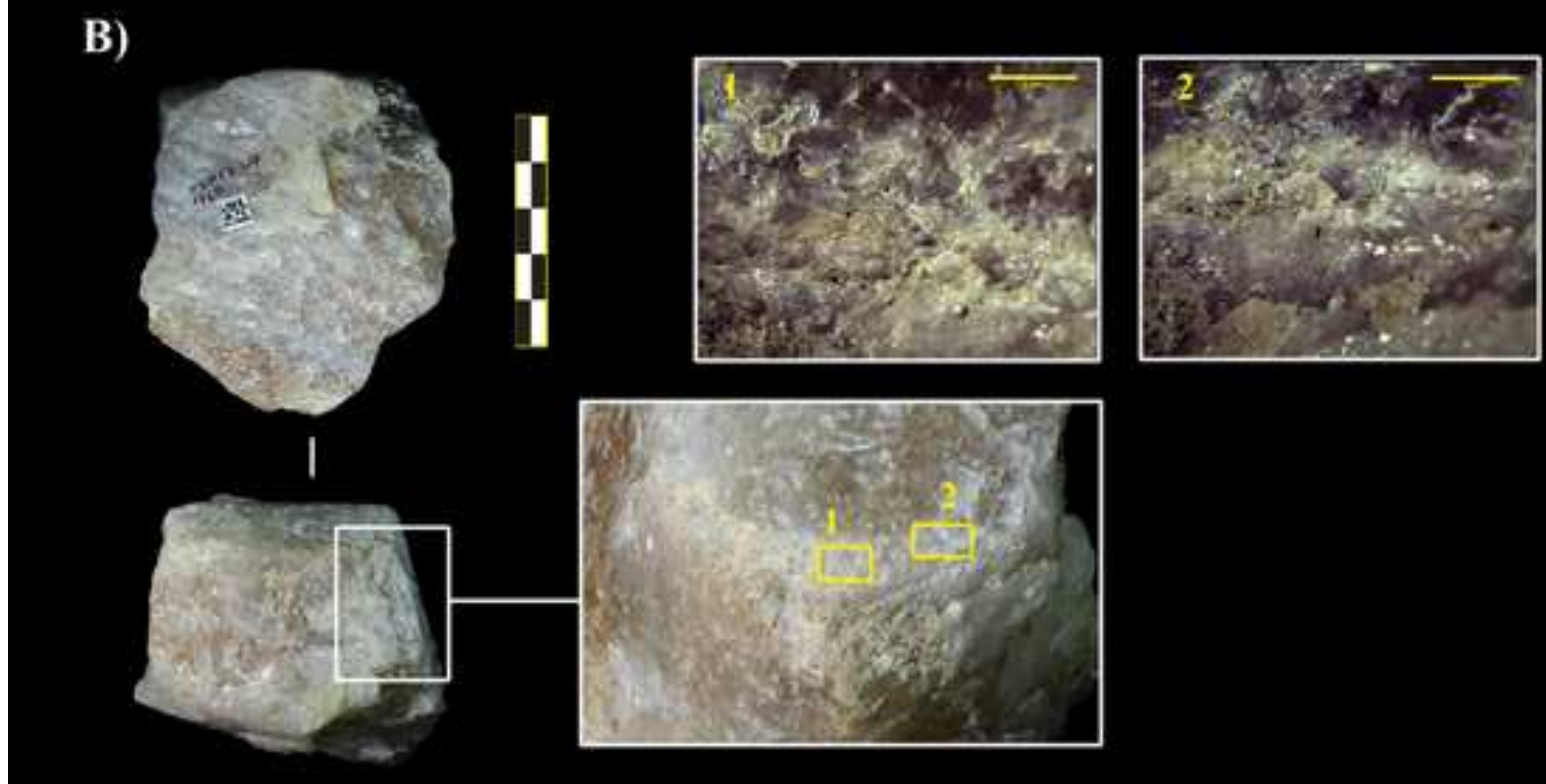

Click here to download high resolution image

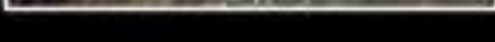




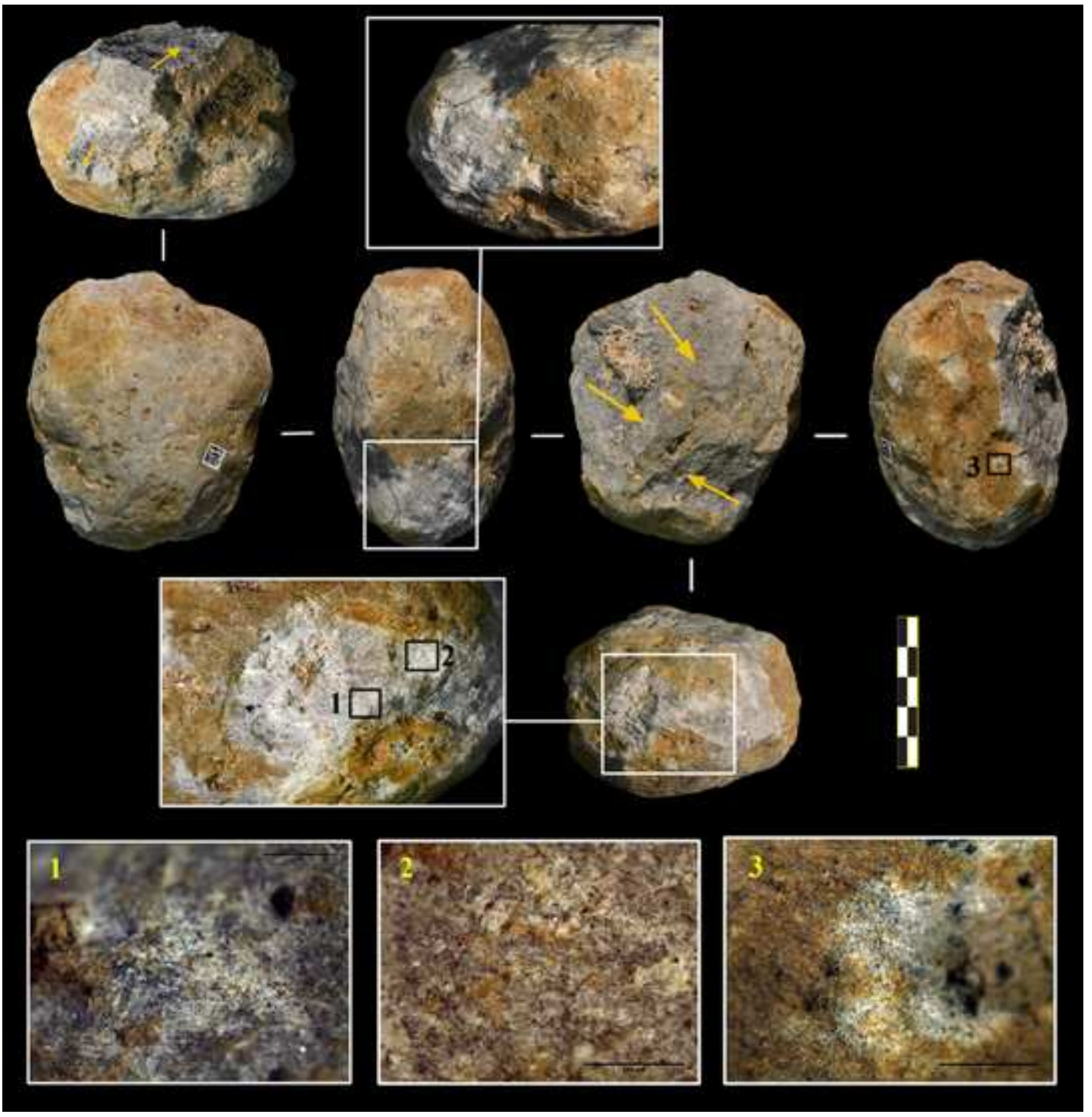


Click here to download high resolution image

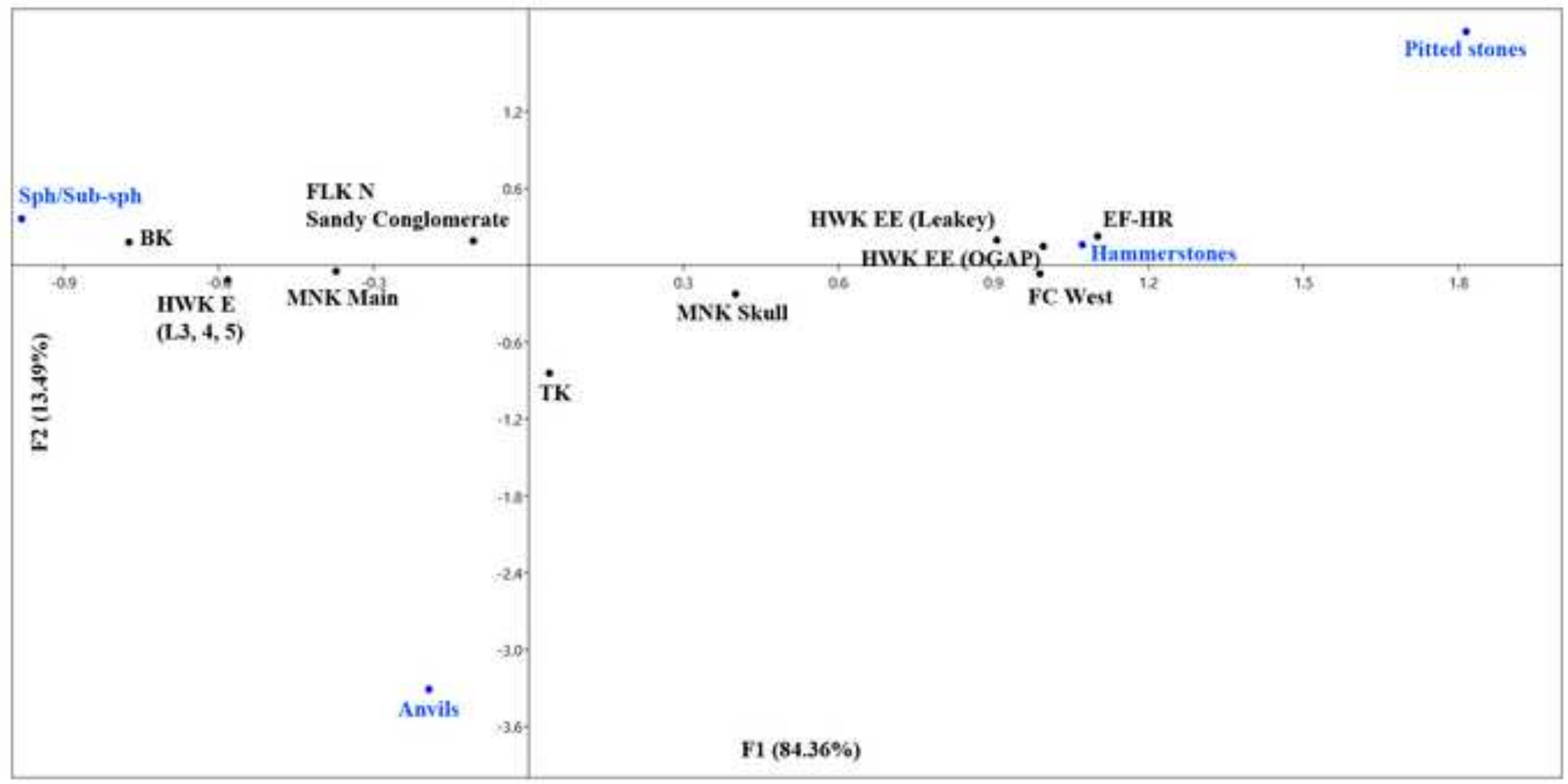


Supplementary Material 1
Click here to download Supplementary Material: SOM 1.docx

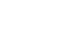

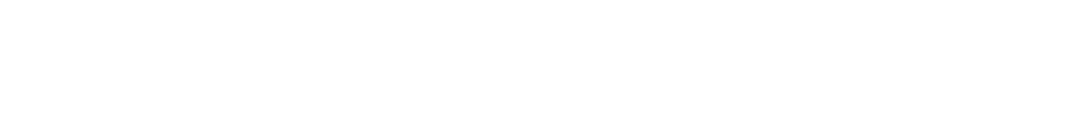
列 (1) (1) (1) (1) (1) (1) (1) (1) (1) . . . 
Supplementary Material 2
Click here to download Supplementary Material: SOM 2.avi

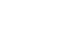

plementary Material: SOM 2.avi

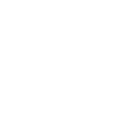

lick here to download Supp 
Supplementary Material 3
Click here to download Supplementary Material: SOM 3.mp4

Supplementary Material 3
Click here to download Supplementary Material: SOM 3.mp4

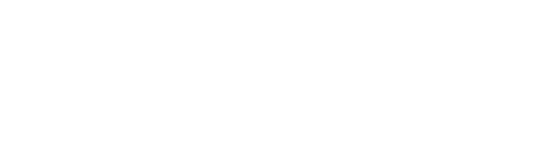

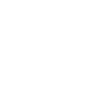

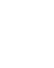
$x^{2}$ (n)

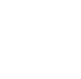
$x^{2}$ $x^{2}$ (1) $x^{2}$ (1) $x^{2}$ $x^{2}$ $x^{2}$ (1) $x^{2}$ $x^{2}$ $x^{2}$ $x^{2}$ (1) 
Supplementary Material 4
Click here to download Supplementary Material: SOM 4.mp4

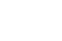

$(2+2$

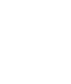

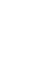

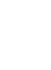

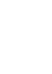

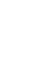
. . . .

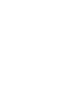

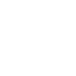
更 更 更 更 更 更 更 更 更 更 更 更 更 更 更 